\title{
Biomass to porous carbon in one step: Directly activated biomass for high performance $\mathrm{CO}_{2}$ storage
}

Norah Balahmar, Abdul Salam Al-Jumialy and Robert Mokaya*

School of Chemistry, University of Nottingham, University Park, Nottingham NG7 2RD, U. K.

E-mail: r.mokaya@nottingham.ac.uk(R.Mokaya) 


\section{Abstract}

This report explores the direct conversion of biomass to activated carbons in one step. We demonstrate the successful conversion of a range of biomass sources, namely, sawdust, the flowering plant Paeonia Lactiflora and seaweed (Sargassum fusiforme), to activated carbons via a direct activation process that negates the need for hydrothermal carbonisation or pyrolysis. This is a departure from established practice that requires that biomass sources be firstly enriched to carbonaceous matter via hydrothermal carbonisation or pyrolysis prior to activation. The direct activation, with $\mathrm{KOH}$ as activating agent, generated activated carbon at yields that are comparable or higher than those of conventional activation routes. The directly activated carbons, whilst offering the advantage of simplicity, lower cost and a greener more sustainable synthesis route, have properties that are similar or superior to those of analogous carbons prepared via conventional methods. In particular the textural properties, surface functionality and level of graphitic ordering was found to be similar to that of conventionally generated activated carbons. Depending on the activation conditions, the porosity of the directly activated carbons may be tailored towards pore channels of size $5-7 \AA$ pores, which favour post-combustion $\mathrm{CO}_{2}$ uptake and thus the carbons capture up to 1.3 and $4.6 \mathrm{mmol} \mathrm{g}^{-1}$ of $\mathrm{CO}_{2}$ at 0.15 and $1 \mathrm{bar}$, respectively, and $25{ }^{\circ} \mathrm{C}$ with high selectivity. On the other hand, at higher levels of activation, the directly activated carbons can be tailored towards possessing a greater proportion of larger micropores $(10-20 \AA$ pores $)$ and small mesopores $(20-30 \AA$ pores $)$ so as to optimize $\mathrm{CO}_{2}$ uptake at moderate to high pressure, for example up to $22 \mathrm{mmol} \mathrm{g}^{-1}$ (at $25{ }^{\circ} \mathrm{C}$ ) and $31 \mathrm{mmol} \mathrm{g}^{-1}$ (at $0{ }^{\circ} \mathrm{C}$ ) and 20 bar. 


\section{Introduction}

The discovery of new materials is a central requirement in many anticipated advances in the energy and sustainability arena. ${ }^{1-3}$ For new materials to be interesting they need to fit into one of three categories; (i) exhibit new or improved desirable properties, (ii) be easier or cheaper to prepare, and (iii) be sustainable. Improved or new properties may be achieved by careful material design based on deep understanding of underlying phenomena, while lower cost and ease of preparation may be possible by the use of new starting (raw) materials or simple reduction of the number of steps required. In this regard, nanostructured carbons prepared via simple processes and which use readily available and low cost precursors are now considered as key materials for the generation and storage of sustainable energy and for environmental remediation. ${ }^{4,5}$ This is typified by the broad class of nanostructured carbons that are currently under intense study for use as, amongst other applications, gas (hydrogen, $\mathrm{CO}_{2}$, methane, etc) storage materials $s^{4,6,7}$ or as electrode materials for supercapacitors. ${ }^{4,8}$ For the next generation of nanostructured carbons, the drive is towards materials that are simple to prepare via cost effective routes, and which may involve use of renewable resources as precursors wherein there is the possibility of valorisation of the starting (raw) materials. Amongst nanostructured carbons, activated carbons are attracting a great deal of interest due to their tuneable pore size, porosity and good chemical stability. ${ }^{4-8}$ A particular attraction of activated carbons is that their 'green' credentials may be enhanced if they are prepared from sustainable biomass resources that would normally be considered as waste.

Recently, we have reported on new synthesis routes to activated carbons generated from sustainable precursors or renewable biomass. ${ }^{9-15}$ The carbons have improved gas $\left(\mathrm{CO}_{2}\right.$ and hydrogen) storage capacity ${ }^{9-14}$ and are excellent electrode materials for supercapacitors. ${ }^{15}$ In general, activated carbons are traditionally synthesized via physical or chemical activation. ${ }^{4-8}$ The former involves gasification of a carbon precursor with oxidizing gases such as steam or air 
at high temperature $\left(800-1100{ }^{\circ} \mathrm{C}\right)$, while for the later, the carbon precursor is thermally treated under inert conditions in the presence of an activating agent $\left(\mathrm{KOH}, \mathrm{NaOH}\right.$ or $\mathrm{ZnCl}_{2}$ etc.). For conversion of biomass to activated carbons, the conventional process is to first convert the biomass into carbon-rich carbonaceous matter, which is then activated. ${ }^{4-15}$ The two main processes for the conversion of biomass to activateable carbonaceous matter are; (i) hydrothermal carbonisation (HTC) ${ }^{16-20}$ and (ii) pyrolysis. ${ }^{21-24}$ Hydrothermal carbonization proceeds via thermochemical decomposition of biomass into so-called hydrochar in the presence of superheated water, ${ }^{16-20}$ while pyrolysis occurs via processes that increase the carbon content of biomass precursors during heating in the absence of oxygen. ${ }^{21-24}$ In the search for sustainable and cheaper biomass-derived activated carbons it is desirable to simplify the synthesis process and in particular to negate the need for hydrothermal carbonisation or pyrolysis prior to activation. In other words, it is desirable to directly activate biomass to activated carbons that have similar or improved yield and/or properties compared to those that are prepared via the conventional, and longer, two-step route incorporating HTC or pyrolysis prior to activation. As far as we know, there are hardly any reports of such direct activation of biomass and no comprehensive data exists on how they compare to conventionally activated carbons. In this report, therefore, we explore the direct activation of several forms of biomass and establish whether such a direct, simpler and cheaper process offers advantages with respect to carbon yield, properties and application as energy materials in gas $\left(\mathrm{CO}_{2}\right)$ storage. We compare the characteristics of directly activated biomass-derived carbons and their $\mathrm{CO}_{2}$ uptake properties to carbons generated via a conventional two-step (HTC + activation) process.

\section{Experimental Section}

\subsection{Material Synthesis}


The carbons were derived from a variety of biomass sources including (i) Eucalyptus wood sawdust, (ii) the flowering plant Paeonia Lactiflora and (iii) seaweed (Sargassum fusiforme) although a number of other biomass precursors may also be utilized. The sawdust, Paeonia Lactiflora or Sargassum fusiforme were either activated directly or first converted to hydrochar, via hydrothermal carbonisation, prior to activation.

For direct activation, the required amount of $\mathrm{KOH}$ was added to sawdust, Paeonia Lactiflora or Sargassum fusiforme and thoroughly mixed. The resulting $\mathrm{KOH} /$ biomass mixture was placed in a ceramic boat and inserted into a tubular furnace and heated (at a ramp rate of $5^{\circ} \mathrm{C} \mathrm{min}^{-1}$ ) to between 600 and $800{ }^{\circ} \mathrm{C}$ and held at the target temperature for $1 \mathrm{~h}$. The resulting carbonaceous matter was recovered and washed with $2 \mathrm{M} \mathrm{HCl}$ at room temperature until all inorganic impurities were removed as confirmed by thermogravimetric analysis. The directly prepared activated carbons were then filtered, washed with deionised water and dried in an oven at $120{ }^{\circ} \mathrm{C}$ for $6 \mathrm{~h}$. The directly activated carbons were designated as SDxTD (from sawdust), PLFxTD (from Paeonia Lactiflora), or SWxTD (from seaweed Sargassum fusiforme) where $\mathrm{x}$ is the $\mathrm{KOH} /$ biomass mass ratio (2 or 4$)$ and $\mathrm{T}$ is the activation temperature $\left(600,700\right.$ or $\left.800{ }^{\circ} \mathrm{C}\right)$.

For conventional activation, the sawdust, Paeonia Lactiflora or Sargassum fusiforme was first converted to hydrochar via hydrothermal carbonisation as follows; an aqueous dispersion of biomass (sawdust, Paeonia Lactiflora or Sargassum fusiforme) at a concentration of $320 \mathrm{~g} \mathrm{l}^{-1}$ was placed in a stainless steel autoclave and heated up to $250^{\circ} \mathrm{C}$ and the temperature held for 2 h. The resulting solid (the hydrochar) was recovered by filtration and washed thoroughly with distilled water and then dried at $120^{\circ} \mathrm{C}$ for $4 \mathrm{~h}$. The hydrochar was then activated as described above. The hydrochar-derived activated carbons were designated as SDxT (from sawdust), PLFxT (from Paeonia Lactiflora) or SWxT (from seaweed Sargassum fusiforme) where $\mathrm{x}$ is the $\mathrm{KOH} /$ carbon mass ratio (2 or 4$)$ and $\mathrm{T}$ the activation temperature $\left(600,700\right.$ or $\left.800{ }^{\circ} \mathrm{C}\right)$.

\subsection{Characterisation of samples}


Thermogravimetric analysis (TGA) was performed using a TA Instruments SDT Q600 analyser under flowing air conditions $(100 \mathrm{~mL} / \mathrm{min})$. Powder XRD analysis was performed using a PANalytical X'Pert PRO diffractometer with $\mathrm{Cu}-\mathrm{K} \alpha$ light source $(40 \mathrm{kV}, 40 \mathrm{~mA})$ with step size of $0.02^{\circ}$ and $50 \mathrm{~s}$ time step. CHN elemental analysis was performed using an Exeter Analytical CE-440 Elemental Analyser. Inorganic (metal) content was determined via ICP-OES analysis using a Perkin Elmer Optima 2000 DV ICP-OES analyser. Raman spectra were recorded using a Horiba-Jobin-Yvon LabRAM Raman microscope with a $532 \mathrm{~nm}$ laser operating at $c a .4 \mathrm{~mW}$ (10\%) and a 600 lines/mm grating. Spectra were collected by averaging 8 acquisitions of $60 \mathrm{~s}$ duration. The Raman shift was calibrated using the Rayleigh peak and the $520.7 \mathrm{~cm}^{-1} \mathrm{Si}$ line from a Si (100) reference sample. Analysis of porosity and determination of textural properties was performed via nitrogen sorption using a Micromeritics ASAP 2020 or 3FLEX sorptometer. Prior to analysis (at $-196{ }^{\circ} \mathrm{C}$ ), the carbon samples were degassed under vacuum at $200{ }^{\circ} \mathrm{C}$ for 12 h. Surface area was calculated using the Brunauer-Emmett-Teller (BET) method applied to adsorption data within the relative pressure $\left(P / P_{o}\right)$ range of $0.02-0.22$. The total pore volume was determined from the nitrogen uptake at close to saturation pressure $\left(P / P_{o} \approx 0.99\right)$. The micropore surface area and micropore volume were determined via $t$-plot analysis. Non-local density functional theory (NL-DFT) was applied to nitrogen adsorption isotherms to determine pore size distribution. SEM images were recorded on a FEI Quanta200 microscope at $5 \mathrm{kV}$ accelerating voltage. Transmission electron microscopy (TEM) images were obtained using a JEOL 2100F instrument operating at $200 \mathrm{kV}$ equipped with a Gatan Orius CCD for imaging. The samples were suspended in distilled water or propanal and dispersed onto lacey carbon support film prior to analysis.

\section{$2.3 \mathrm{CO}_{2}$ uptake measurements}

$\mathrm{CO}_{2}$ uptake was determined using a Hiden Isochema Intelligent Gravimetric Analyser (IGA003). Before $\mathrm{CO}_{2}$ uptake measurements, the carbon samples were degassed at $200{ }^{\circ} \mathrm{C}$ under 
vacuum for several hours. Adsorption-desorption isotherms were measured at $25{ }^{\circ} \mathrm{C}$ or $0{ }^{\circ} \mathrm{C}$ over $\mathrm{CO}_{2}$ pressure range of $0-20$ bar.

\section{Results and Discussion}

The aim of this study was to demonstrate a general route for the direct conversion of biomass to activated carbon. For this reason, we used several types of biomass as precursor, and herein discuss the findings for three precursors, namely; (i) Eucalyptus sawdust, (ii) the flowering plant Paeonia Lactiflora and (iii) seaweed Sargassum fusiforme. To avoid unnecessary duplication, our discussions are mainly on data obtained for the Eucalyptus sawdust (which is hereinafter referred to as sawdust) although similar results were obtained for the other biomass precursors. Prior to activation, we determined the carbon content of the sawdust compared to the sawdustderived hydrochar (SD hydrocahr) as shown in Table 1. As expected the carbon content (given as wt\%) increases following hydrothermal carbonisation (HTC) from $46.4 \%$ for the sawdust to $57.4 \%$ for the hydrochar. The $\mathrm{H}$ content remains unchanged, with the effect that the $\mathrm{O}$ content reduces following hydrothermal carbonisation.

\begin{tabular}{llllllll} 
Table 1. & Sample & $\mathrm{C}[\%]$ & $\mathrm{H}[\%]$ & $\mathrm{O}[\%]$ & $(\mathrm{O} / \mathrm{C})^{\mathrm{a}}$ & $(\mathrm{H} / \mathrm{C})^{\mathrm{a}}$ & $\begin{array}{r}\text { Elemental } \\
\text { of }\end{array}$ \\
\cline { 2 - 6 } composition \\
and & Sawdust & 46.4 & 5.8 & 47.8 & 0.773 & 1.500 & $\begin{array}{r}\text { sawdust, SD } \\
\text { hydrochar } \\
\text { activated }\end{array}$ \\
carbons & SD Hydrochar & 57.4 & 5.6 & 37.0 & 0.483 & 1.171 & ('Atomic \\
ratio). & SD2600D & 71.4 & 0.7 & 27.9 & 0.293 & 0.118 & \\
& SD2600 & 72.3 & 0.7 & 27.0 & 0.280 & 0.116 & \\
& SD2700 & 75.6 & 0.3 & 24.1 & 0.239 & 0.048 & \\
& SD2800D & 72.4 & 0.3 & 28.3 & 0.293 & 0.049 & \\
& SD2800 & 85.6 & 0.4 & 14.0 & 0.123 & 0.056 & \\
& & 85.2 & 0.1 & 14.8 & 0.130 & 0.014 &
\end{tabular}




\begin{tabular}{llllll} 
SD4800D & 85.8 & 0.3 & 13.9 & 0.122 & 0.042 \\
SD4800 & 89.7 & 0.1 & 10.3 & 0.086 & 0.013 \\
\hline
\end{tabular}

We monitored the activated carbon yield to ascertain whether the direct activation route offered any disadvantages or otherwise. For conventional activation via HTC, the carbon yield from sawdust to hydrochar was ca. $43 \%$, which is similar to what has previously been reported. ${ }^{19,25-27}$ The yield of activated carbons from the hydrochar (at $\mathrm{KOH} /$ carbon ratio of 2) varied between $32 \%$ (at $800{ }^{\circ} \mathrm{C}$ ) and $47 \%$ (at $600{ }^{\circ} \mathrm{C}$ ), which is in agreement with previous studies. ${ }^{9,14,28-31}$ Thus the yield of activated carbon with respect to the sawdust was between $14 \%$ (at $800{ }^{\circ} \mathrm{C}$ ) and $20 \%$ (at $600{ }^{\circ} \mathrm{C}$ ). On the other hand the carbon yield via the direct activation route was between $22 \%$ (at $800{ }^{\circ} \mathrm{C}$ ) and $30 \%$ (at $600{ }^{\circ} \mathrm{C}$ ). Thus the activated carbon yields (with respect to the sawdust biomass) are higher for direct activation than for the conventional route. Similar trends in yield were observed for activated carbons derived from Paeonia Lactiflora and seaweed (Sargassum fusiforme).

We confirmed that the activated carbons prepared directly were fully carbonaceous by performing thermogravimetric analysis (TGA). The TGA curves of the directly synthesised (SD2800D and SD4800D) and analogous conventionally prepared (SD2800 and SD4800) activated carbons are very similar and both show virtually no residual mass at $700{ }^{\circ} \mathrm{C}$ 
(Supporting Figure S1). Additionally both the directly and conventionally synthesised activated carbons have a similar level of thermal stability which suggests similar levels of graphitisation. Furthermore, in both cases the carbons prepared at higher activation temperature show greater resistance to combustion as expected. We also determined the metal content of the carbons via ICP-OES analysis using a Perkin Elmer Optima 2000 DV ICP-OES with S10 autosampler. We analysed for $\mathrm{K}, \mathrm{Na}, \mathrm{Ca}, \mathrm{Fe}, \mathrm{Mn}, \mathrm{Ba}, \mathrm{Mg}$, and found only trace amounts of $\mathrm{Ca}$ (ca. $0.2 \mathrm{wt} \%$ ), and hardly detected amounts of $\mathrm{K}, \mathrm{Mg}$ and $\mathrm{Na}$, all of which were typically less than $0.1 \mathrm{wt} \%$. The amounts were similar for analogous directly and conventionally activated carbons. It appears therefore that direct activation does not have any effect on the nature of the carbon. This was confirmed by both powder XRD patterns (Supporting Figure S2) and elemental analysis data (Table 1). The XRD patterns suggest a similar level of graphitic ordering for the conventional and directly synthesised samples. The elemental analysis data in Table 1 shows that the $\mathrm{C}, \mathrm{H}$ and $\mathrm{O}$ content is very similar, and that for all sample sets, the $\mathrm{C}$ content in the activated carbons increases for samples prepared at higher activation temperature.

To further ascertain the similarity between the directly activated and conventionally prepared activated carbons, we performed Raman analysis. The Raman spectra are shown in Figure 1. The carbons exhibit bands at $1340-1350 \mathrm{~cm}^{-1}$ and $1586-1590 \mathrm{~cm}^{-1}$ that are the Dpeak (disordered carbon) and the G-peak (graphitic domains), respectively. ${ }^{32}$ The spectra show no discernible differences between the two sets of samples. The ratio of peak intensity (i.e., area) of the D-peak to G-peak $\left(\mathrm{I}_{\mathrm{D}} / \mathrm{I}_{\mathrm{G}}\right)$, based on the two-band fitting model is very similar for the two sets of samples (Supporting Table $\mathrm{S} 1$ ). The $\mathrm{I}_{\mathrm{D}} / \mathrm{I}_{\mathrm{G}}$ ratio is 0.78 and 0.79 for samples SD2600 and SD2600D, respectively, increases to 0.81 and 0.83 for SD2700 and SD2700D, respectively, is similar (0.84) for samples prepared at $800{ }^{\circ} \mathrm{C}$ and $\mathrm{KOH} /$ carbon ratio of 2 (SD2800 and SD2800D) and highest at 0.86 and 0.87 for SD4800 and SD4800D, respectively. The similar $\mathrm{I}_{\mathrm{D}} / \mathrm{I}_{\mathrm{G}}$ ratio confirms that direct activation does not alter the nature of 
or level of graphitisation in activated carbons, which is consistent with the XRD patterns (Supporting Figure $\mathrm{S} 2$ ). $\mathrm{I}_{\mathrm{D}} / \mathrm{I}_{\mathrm{G}}$ ratio of $0.78-0.87$ is consistent with the amorphous (i.e., nongraphitic) nature of the carbons. ${ }^{32}$ The ratio increases for carbons prepared at higher temperature, suggesting that greater activation disrupts any graphitic domains that are present.
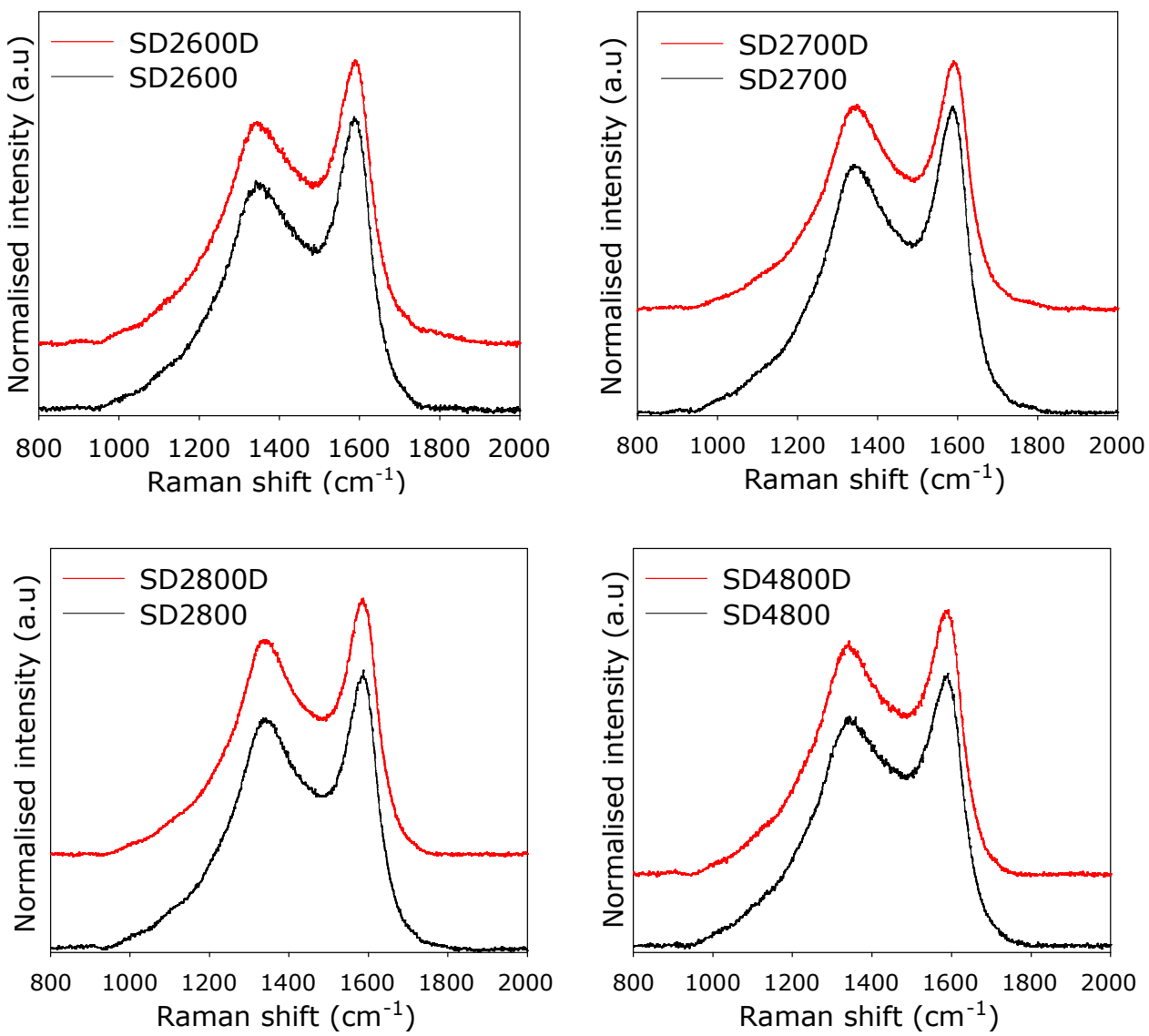

Figure 1. Raman spectra of sawdust-derived directly activated (SDxTD) and conventionally generated (SDxT) carbons. See experimental section for sample designation.

To probe the nature and similarity of functional groups on the conventional and directly prepared activated carbons, we used IR spectroscopy. The IR spectra of both sets of carbons (Supporting Figure S3) show the $\mathrm{C}-\mathrm{OH}$ stretch band at ca. $3430 \mathrm{~cm}^{-1}$, and $\mathrm{C}-\mathrm{OH}$ bend band at ca. $1630 \mathrm{~cm}^{-1} \cdot{ }^{9,19,29}$ The IR spectra also exhibit peaks attributable to $\mathrm{C}-\mathrm{O}$ vibrations at ca. 1385 
$\mathrm{cm}^{-1}$ (sharp peak), and a $\mathrm{C}=\mathrm{O}$ peak at $1710 \mathrm{~cm}^{-1} \cdot 9,19,29$ For both sets of samples, the intensity of the peaks decreases at higher activation temperature and at higher $\mathrm{KOH} /$ carbon ratio, i.e., at higher levels of activation. This decrease in peak intensity, which signifies a decrease in Ofunctional groups, is consistent with the trend in elemental composition (i.e., reduction in $\mathrm{O}$ content) as shown in Table 1. Thus the IR spectra of samples SD2600D and SD2600, which are prepared at $600{ }^{\circ} \mathrm{C}$ and $\mathrm{KOH} /$ carbon ratio of 2 and have $\mathrm{O}$ content of $27-28 \mathrm{wt} \%$ (Table 1), exhibit the most prominent peaks (Figure S3A). The intensity of the O-functional groups decreases for samples SD2800D and SD2800 (Figure S3B), which are prepared at $800{ }^{\circ} \mathrm{C}$ and $\mathrm{KOH} /$ carbon ratio of 2 and have lower $\mathrm{O}$ content of $14-15 \mathrm{wt} \%$ (Table 1). This trend in decrease of the intensity of IR peaks continues for the most activated samples SD4800D and SD4800 (Figure S3B), which have lowest O content of $10-14$ wt $\%$. It is, however, noteworthy that there is no difference in the IR spectra of the directly prepared carbons when compared to the conventional samples. This confirms that direct activation does not alter the surface functionality of activated carbons.

The nitrogen sorption isotherms of sawdust-derived directly activated and conventionally synthesised carbons, prepared at $\mathrm{KOH} /$ carbon ratio of 2, are shown in Figure 2 and the corresponding pore size distribution (PSD) curves are given in Figure 3. At any given activation temperature $\left(600,700\right.$ or $\left.800{ }^{\circ} \mathrm{C}\right)$, the isotherms of the two sets of samples are generally similar implying that comparable levels of porosity are generated via either direct or conventional synthesis. Only at $800{ }^{\circ} \mathrm{C}$ does the conventional sample (SD2800) appear to adsorb more nitrogen at higher relative pressures $(\mathrm{P} / \mathrm{Po}>0.3)$ compared to the equivalent directly activated carbon (SD2800D). In all cases, however, both sets of carbons have similar adsorption at low relative pressure $(\mathrm{P} / \mathrm{Po}<0.2)$. It is interesting to observe from the PSD curves in Figure 3 that, at any given activation temperature, the two sets of samples have very similar micropore pore size distribution. Furthermore, the mesopore and macropore size distribution $(20-4000 \AA)$ of both 
sets of samples prepared under identical conditions is also similar as shown by wide pore size distribution plots (Supporting Figure S4). This confirms that the size of pores, and the overall pore channel system generated via direct activation is virtually identical to that from conventional synthesis. Overall, therefore, direct activation causes no disadvantages with respect to the nature of the porosity in the carbons

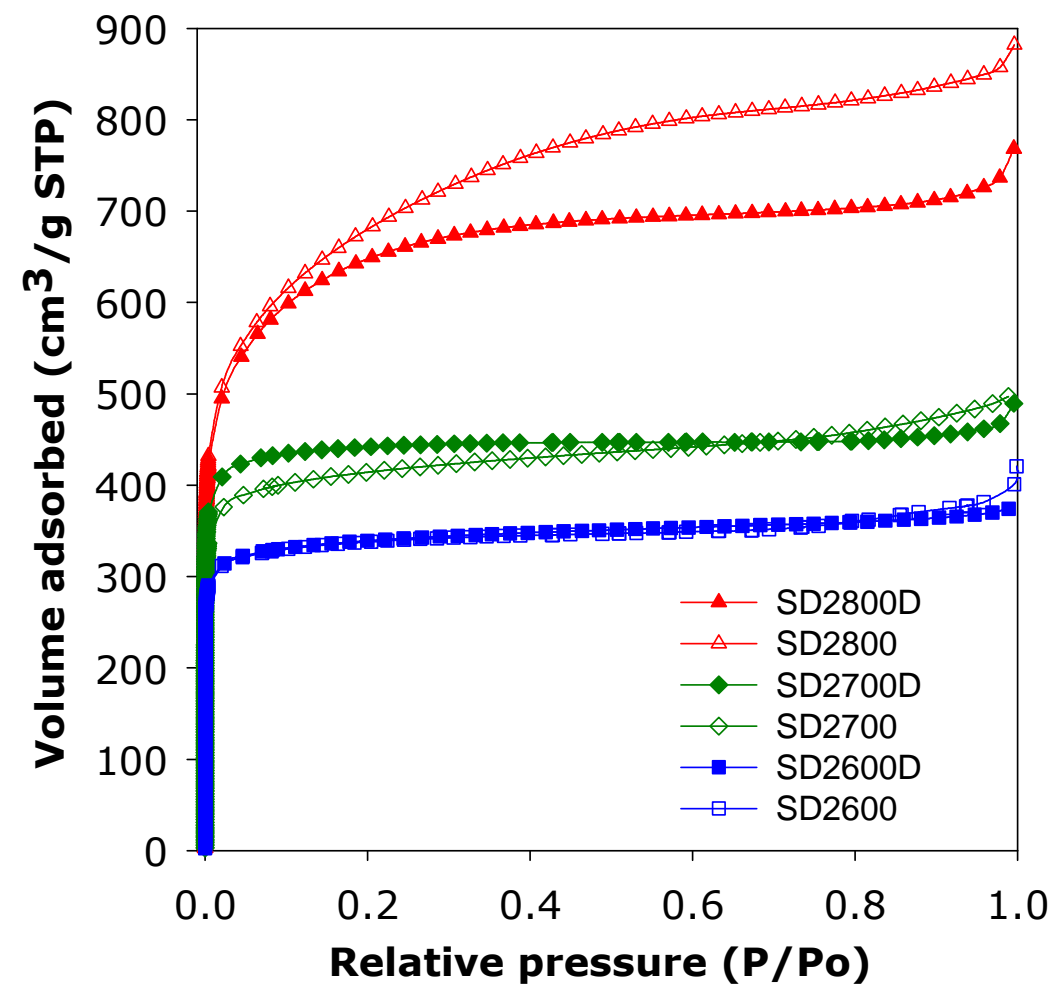

Figure 2. Nitrogen sorption isotherms of sawdust-derived directly activated (SD2TD) and conventionally generated (SD2T) carbons prepared at $\mathrm{KOH} /$ carbon ratio of 2 and various temperatures $(T)$. See experimental section for sample designation. 

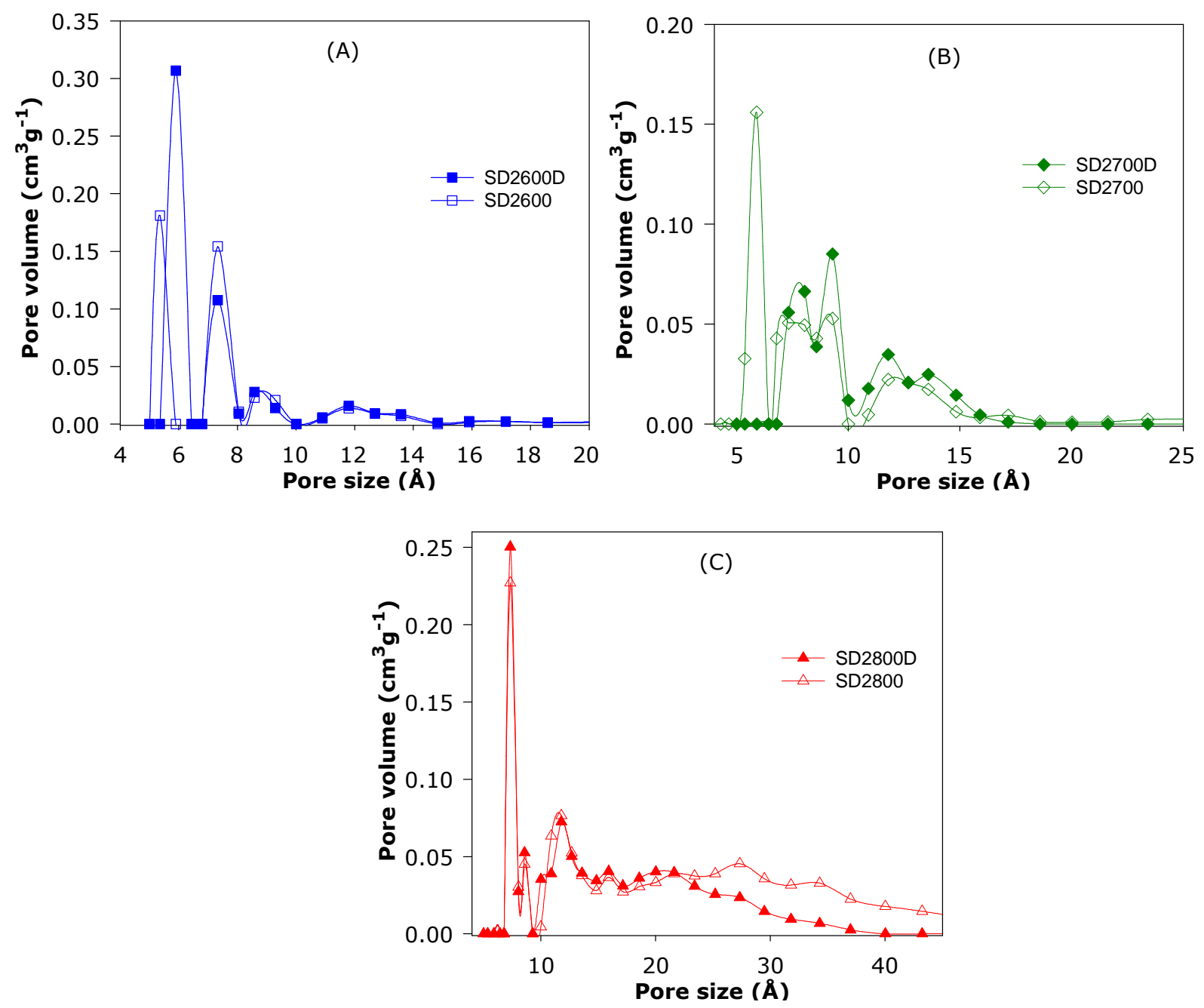

Figure 3. Pore size distribution (PSD) curves of sawdust-derived directly activated (SD2TD) and conventionally generated (SD2T) carbons prepared at $\mathrm{KOH} /$ carbon ratio of 2 and; (A) $600{ }^{\circ} \mathrm{C}$, (B) $700{ }^{\circ} \mathrm{C}$ and (C) $800{ }^{\circ} \mathrm{C}$. See experimental section for sample designation.

The textural parameters of the two sets of carbon (directly and conventionally synthesised) are summarised in Table 2. In general, the surface area and pore volume of the directly activated carbons is comparable to that of equivalent conventional samples. This is an important observation, which confirms that porosity is not compromised when activation is performed via the more environmentally friendly direct route. Indeed, in some cases the surface area and the level of microporosity (i.e., micropore surface area and pore volume) is higher for the directly activated carbons. The pore size data in Table 2 confirms that there is virtually no 
change in the size of pores generated in directly activated carbons when compared to equivalent conventional samples. All samples possess small micropores along with some larger micropores wherein the proportion of the later increases at higher activation temperature. Similar trends that confirm comparable porosity are observed for samples prepared at $800{ }^{\circ} \mathrm{C}$ and $\mathrm{KOH} /$ carbon ratio of 4 either via the direct (SD4800D) or conventional (SD4800) route (Supporting Figure S5 and S6, and Table 2). It is worth noting that for both synthesis routes, activation of the carbonaceous matter using $\mathrm{KOH}$ first proceeds according to the following equation; $\mathrm{KOH}+\mathrm{C} \rightarrow 2 \mathrm{~K}+3 \mathrm{H}_{2}+$ $2 \mathrm{~K}_{2} \mathrm{CO}_{3}$. The generated $\mathrm{K}$ is intercalated within the carbon layers, while $\mathrm{K}_{2} \mathrm{CO}_{3}$ decomposes at high temperature yielding $\mathrm{K}_{2} \mathrm{O}+\mathrm{CO}_{2}$. Porosity in the activated carbon is generated via $\mathrm{C}$ etching according to the equation given above, and also via the generated $\mathrm{CO}_{2}$ poring through the carbon substrate during the activation process. Furthermore, the carbon substrate reacts with the $\mathrm{CO}_{2}$, yielding $\mathrm{CO}$ whilst generating microporosity. After activation, washing with water to remove any inorganic salts and residues generates or releases further porosity in the activated carbon.

Table 2. Textural properties and $\mathrm{CO}_{2}$ uptake of directly activated or conventionally activated carbons derived from sawdust biomass

\begin{tabular}{llllllr}
\hline Sample & $\begin{array}{l}\text { Surface area }^{\mathrm{a}} \\
\left(\mathrm{m}^{2} \mathrm{~g}^{-1}\right)\end{array}$ & $\begin{array}{l}\text { Pore volume }^{\mathrm{b}} \\
\left(\mathrm{cm}^{3} \mathrm{~g}^{-1}\right)\end{array}$ & $\begin{array}{l}\text { Pore size } \\
(\AA)\end{array}$ & \multicolumn{2}{l}{$\begin{array}{l}\mathrm{CO}_{2} \text { uptake }^{\mathrm{d}} \\
\left(\mathrm{mmol} \mathrm{g}^{-1}\right)\end{array}$} & \\
\hline SD2600D & $1281(1119)$ & $0.57(0.45)$ & $6 / 7 / 9$ & 1.3 & 4.5 & 10.3 \\
SD2600 & $1202(1133)$ & $0.65(0.49)$ & $5 / 7 / 9$ & 1.3 & 4.4 & 9.7 \\
SD2700D & $1575(1535)$ & $0.80(0.70)$ & $8 / 9 / 12$ & 1.3 & 4.6 & 12.3 \\
SD2700 & $1557(1294)$ & $0.75(0.53)$ & $6 / 8 / 12$ & 1.3 & 4.6 & 12.1 \\
SD2800D & $2274(1923)$ & $1.20(0.90)$ & $7 / 12 / 20$ & 0.8 & 3.6 & 17.5 \\
SD2800 & $2377(1512)$ & $1.40(0.70)$ & $7 / 12 / 25$ & 0.8 & 3.6 & 18.1 \\
SD4800D & $2980(478)$ & $2.10(0.30)$ & $8 / 12 / 30$ & 0.5 & 2.7 & 21.8 \\
SD4800 & $2783(694)$ & $1.80(0.36)$ & $8 / 12 / 30$ & 0.6 & 3.0 & 21.7 \\
\hline
\end{tabular}

The values in the parenthesis refer to: ${ }^{\mathbf{a}}$ micropore surface area and ${ }^{\mathbf{b}}$ micropore volume. ${ }^{\mathbf{c}}$ Pore size distribution maxima obtained from NLDFT analysis. ${ }^{\mathrm{e}} \mathrm{CO}_{2}$ uptake at $25{ }^{\circ} \mathrm{C}$ and various pressures (i.e., 0.15 bar, 1 bar and 20 bar). 
To test the general applicability of the direct biomass activation process, we used two other precursors, namely, the flowering plant Paeonia Lactiflora and seaweed Sargassum fusiforme. Paeonia Lactiflora derived activated carbons generated via the HTC route (sample PLF2800) or directly (sample PLF2800D) at a KOH/carbon ratio of 2 and activation temperature of $800{ }^{\circ} \mathrm{C}$ exhibited very similar nitrogen sorption isotherms and pore size distribution curves (Supporting Figure S7). The directly activated PLF2800D sample has higher surface area and pore volume of $2349 \mathrm{~m}^{2} / \mathrm{g}$ and $1.48 \mathrm{~cm}^{3} / \mathrm{g}$, respectively, compared to $1908 \mathrm{~m}^{2} / \mathrm{g}$ and $1.20 \mathrm{~cm}^{3} / \mathrm{g}$ for the conventional PLF2800 sample (Supporting Table S2). Nevertheless, the extent of microporosity (as indicated by micropore surface area and pore volume) is similar for the two samples at ca. $80 \%$ of surface area and $60 \%$ of pore volume, which is consistent with their almost identical pore size distribution (Supporting Figure S7 and Table S2). For seaweed (Sargassum fusiforme) derived activated carbons, the direct route appears to generate samples with higher levels of porosity compared to the conventional route (Supporting Figure S8 and Table S3). For example, at $\mathrm{KOH} /$ carbon ratio of 2 and $800^{\circ} \mathrm{C}$, the directly activated SW2800D sample has a surface area of $3095 \mathrm{~m}^{2} / \mathrm{g}$ and pore volume of $1.68 \mathrm{~cm}^{3} / \mathrm{g}$, which are respectively $50 \%$ and $80 \%$ higher than for the conventional SW2800 sample $\left(2085 \mathrm{~m}^{2} / \mathrm{g}\right.$ and $\left.0.93 \mathrm{~cm}^{3} / \mathrm{g}\right)$. However, the pore size distribution remains largely similar for the two classes of activated carbons (Supporting Figure S9 and Table S3). It is interesting that despite possessing higher porosity, the directly activated samples exhibit PSD that is very similar to that of the equivalent conventionally prepared carbon. The overall picture that emerges from the porosity data of carbons from all three precursors, and from their XRD patterns (Supporting Figure S2 and S10) is that direct activation offers a viable route to activated carbons that offer some advantages in terms of greater porosity but with little or no variation in pore size. 
The direct activation process was explored further by observing SEM images of directly activated carbons and comparing them to those prepared via the conventional route. For sawdust derived carbons, we firstly note that the morphology of the raw sawdust (Supporting Figure S11) is similar to what has previously been reported. ${ }^{33}$ For both direct and conventional activation, the morphology of the activated carbons, as shown in Figure 4 (and Supporting Figure 12), is radically different from the fibrous nature of the sawdust (Supporting Figure S11). In both cases the morphology of the activated carbons is dominated by particles with smooth surfaces and large conchoidal cavities, which is consistent with what has previously been reported for hydrochar-derived activated carbons. ${ }^{7,9,33}$ However, there is an important difference between the two sets of carbons wherein the directly activated carbons show much greater connectivity giving the impression of larger monolith-like particles. This greater connectivity in the directly activated carbons (Figure 4 and Supporting Figure S12) may be a preserved characteristic from the sawdust particles (Supporting Figure S11) as opposed to the conventionally prepared samples that are derived from hydrochar that has a significant proportion of stand-alone spherical particles. ${ }^{9,33}$ The SEM images of activated seaweed (Sargassum fusiforme) also show similar trends with the directly activated carbons exhibiting much greater connectivity with particle morphology akin to monoliths as opposed to distinct standalone particles for the conventionally activated samples (Supporting Figure S13).

The pore channel ordering of both sets of activated carbons was observed by TEM analysis as shown in Figure 5. Both sets of samples have wormhole type pores that are typical for activated carbons. ${ }^{34,35}$ From the TEM images it is clear that there is no difference in the pore channel type meaning that direct activation does not alter the nature of the pores. The TEM images for both sets of activated carbons show no evidence of the presence of graphitic domains, which is consistent with the XRD patterns (Supporting Figure S2). 

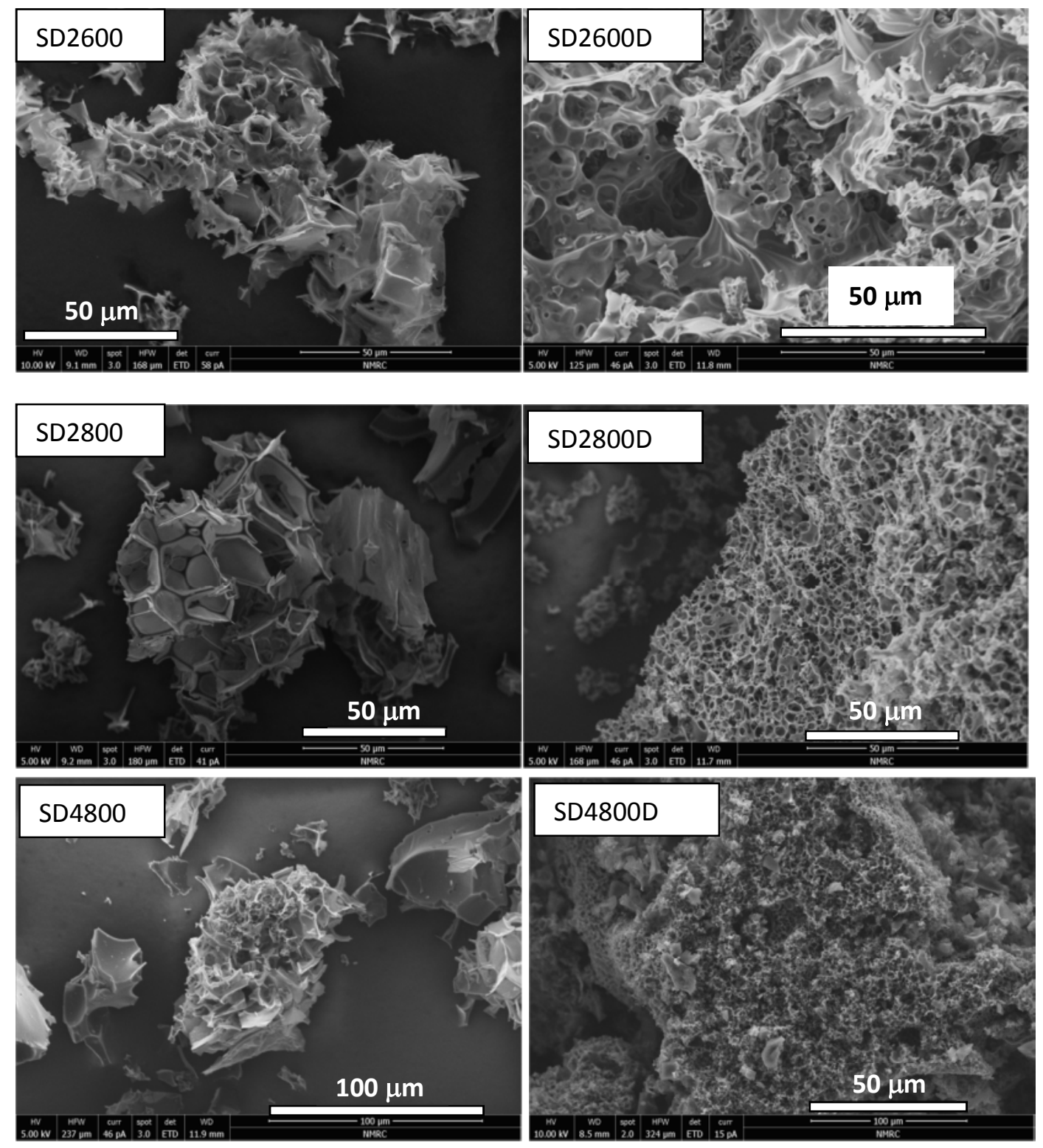

Figure 4. Representative SEM images of sawdust-derived directly activated (SDxTD) and conventionally generated (SDxT) carbons. See experimental section for sample designation. 

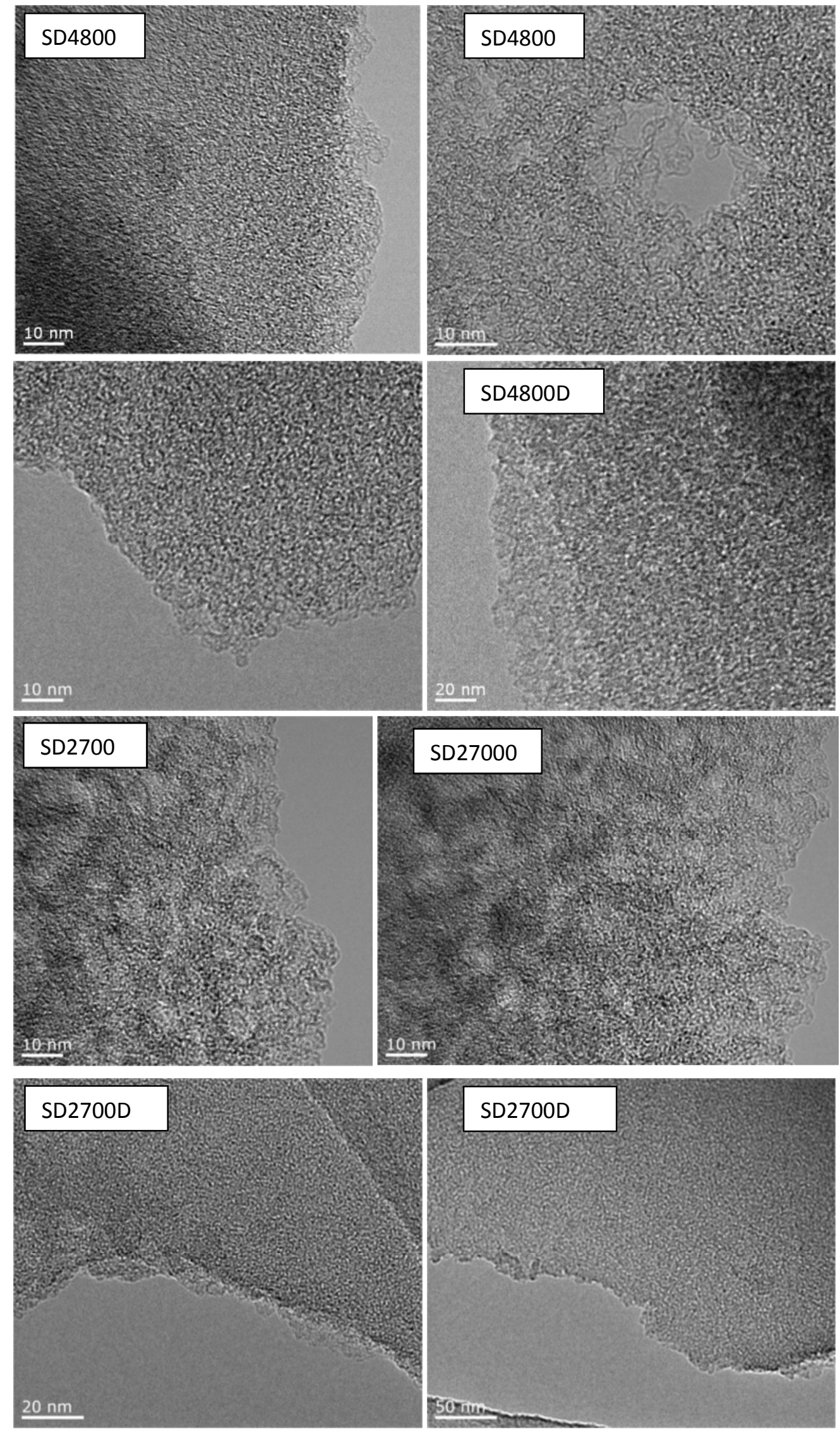

Figure 5. TEM images of sawdust-derived directly (SDxTD) and conventionally (SDxT) activated carbons. See experimental section for sample designation. 
Activated carbons derived from biomass have recently attracted a great deal of attention as solid state stores for energy related gases such as $\mathrm{CO}_{2}$ and $\mathrm{H}_{2}{ }^{4,9-12}$ However, in previous studies, the activated carbons have been prepared via routes that include either hydrothermal carbonisation or pyrolysis prior to the activations step., ${ }^{4,-12}$ Given that the textural properties of the directly activated carbons are similar to those of samples prepared via the longer hydrothermal carbonisation route, we determined their $\mathrm{CO}_{2}$ uptake and compared it to that of analogous conventionally activated samples. The capacity for $\mathrm{CO}_{2}$ capture and storage was performed at room temperature $\left(25{ }^{\circ} \mathrm{C}\right)$ and $0{ }^{\circ} \mathrm{C}$ and pressure range of 0 to 20 bar. The $\mathrm{CO}_{2}$ uptake isotherms for conventionally synthesised (SDxT) and directly activated (SDxTD) carbons are shown in Figure 6 (and Supporting Figure S14) and the storage capacity at various pressures $(0.15,1$ and 20 bar) is stated in Table 2. For SD2 samples prepared at $\mathrm{KOH} /$ carbon ratio of 2, the storage capacity at 1 bar (Figure $6 \mathrm{~B}$ ) ranges from $3.6 \mathrm{mmol} \mathrm{g}^{-1}$ for samples prepared at $800{ }^{\circ} \mathrm{C}$ (SD2800 and SD2800D), to between 4.4 and $4.6 \mathrm{mmol} \mathrm{g}^{-1}$ for samples prepared at 600 and 700 ${ }^{\circ} \mathrm{C}$. It is also clear that the uptake of the directly activated samples very closely matches that of analogous conventionally activated carbons. Thus despite being prepared via a simpler, cheaper and more direct route, the directly activated carbons are able to achieve very high gravimetric $\mathrm{CO}_{2}$ uptake that is amongst the highest ever reported for porous carbons (Table S4). ${ }^{9-12,34-48} \mathrm{~A}$ similar trend is observed for SD4 samples (Table 2), which however show lower $\mathrm{CO}_{2}$ uptake at 1 bar due to their more mesoporous nature (i.e., possess lower levels of microporosity). We also report in Table 2 the $\mathrm{CO}_{2}$ uptake at 0.15 bar so as to mimic post-combustion flue gas streams from power stations which typically consist of ca. $15 \% \mathrm{CO}_{2}$ with the remainder being mainly $\mathrm{N}_{2}$ (70-75\%), and water (5-7\%). ${ }^{49,50}$ The $\mathrm{CO}_{2}$ uptake at 0.15 bar ranges between 0.8 and $1.3 \mathrm{mmol}$ $\mathrm{g}^{-1}$ for SD2 samples and is ca. $0.6 \mathrm{mmol} \mathrm{\textrm {g } ^ { - 1 }}$ for SD4 samples. Uptake of $1.3 \mathrm{mmol} \mathrm{g}^{-1}$ at such low pressure is at the high end of what has previously been observed and correlates well with the microporosity of the samples. ${ }^{9-12,34-48}$ On the other hand, at 20 bar (Figure 6A), the $\mathrm{CO}_{2}$ uptake 
correlates with the total surface area, which means that for sawdust-derived carbons, the directly activated samples generally have greater storage capacity (Table 2) that reaches a high of ca. 22 mmol g ${ }^{-1}$ for SD4 carbons.
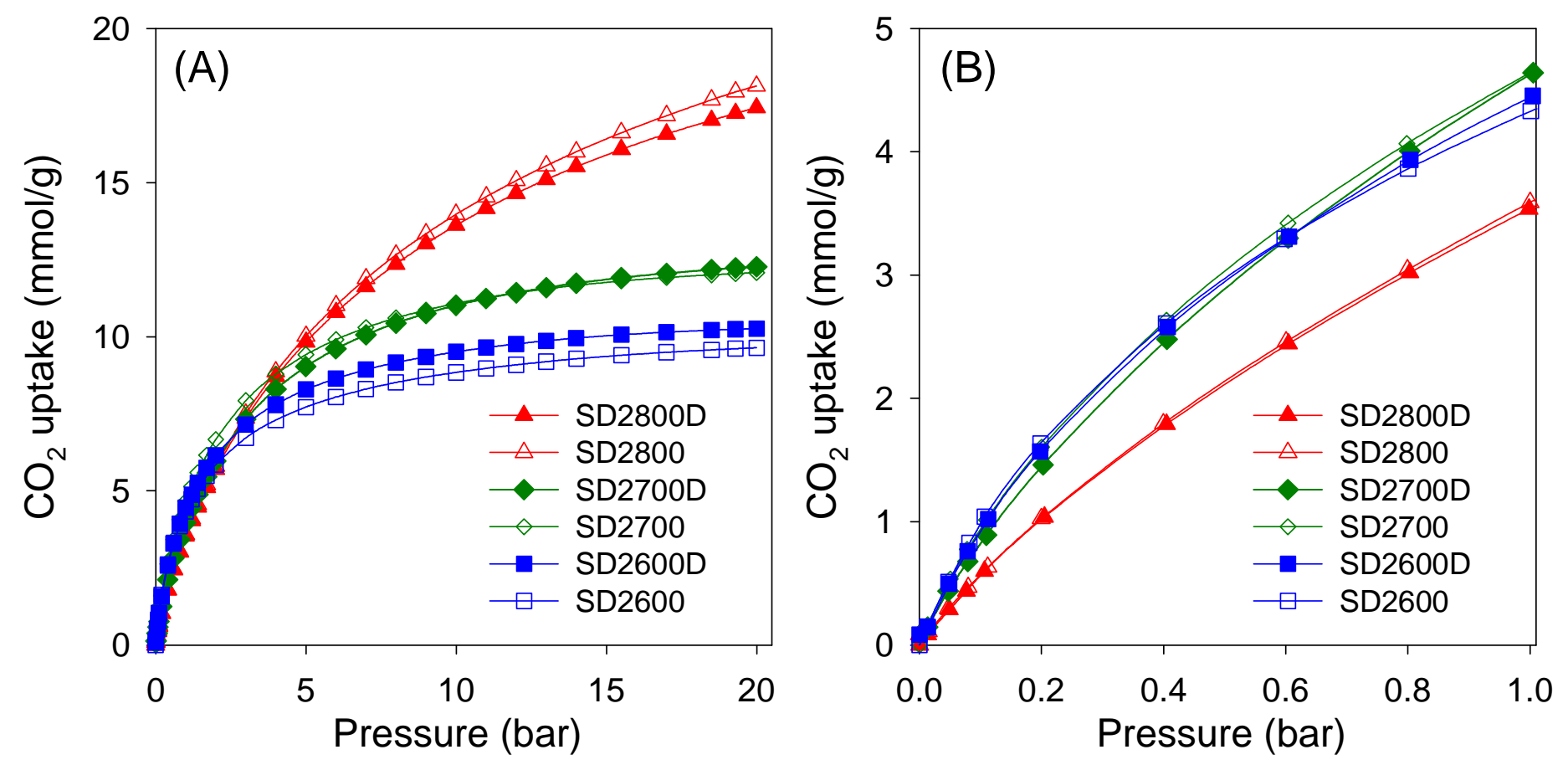

Figure 6. $\mathrm{CO}_{2}$ uptake isotherms at $25{ }^{\circ} \mathrm{C}$ and $0-20$ bar (A) and $0-1$ bar (B) for sawdustderived directly (SD2TD) and conventionally (SD2T) activated carbons. See experimental section for sample designation.

We assessed the selectivity of one of the better performing directly synthesised samples (SD2700D) for $\mathrm{CO}_{2}$ uptake by comparing the relative amounts of $\mathrm{CO}_{2}$ and $\mathrm{N}_{2}$ stored at $25{ }^{\circ} \mathrm{C}$ and 1 bar as shown in Figure 7. At 1 bar, sample SD2700 has $\mathrm{CO}_{2}$ storage capacity of $4.6 \mathrm{mmol} \mathrm{g}^{-1}$, which is far greater than the $\mathrm{N}_{2}$ uptake of $0.22 \mathrm{mmol} \mathrm{g}^{-1}$ (Figure 7), which translates to an equilibrium $\mathrm{CO}_{2} / \mathrm{N}_{2}$ adsorption ratio of 21 . The $\mathrm{CO}_{2} / \mathrm{N}_{2}$ adsorption ratio of 21 for sample SD2700D is higher than values of between 5 and 11 that are typically observed for 
carbon materials, ${ }^{26,43,51,52}$ and comparable to that of heavily doped N-rich carbons, ${ }^{53}$ or highly microporous organic salt-derived carbons. ${ }^{41} \mathrm{We}$ also estimated the selectivity for $\mathrm{CO}_{2}$ adsorption from simulated post-combustion flue gas streams in which the proportion of $\mathrm{CO}_{2}$ is ca. $15 \%$ with the remainder being mainly nitrogen by considering the relative uptake of $\mathrm{CO}_{2}$ at 0.15 bar and $\mathrm{N}_{2}$ uptake at 0.85 bar. This is based on the fact that flue gas streams from fossil fuel power stations contain only ca. $15 \% \mathrm{CO}_{2}$, with the rest being mainly $\mathrm{N}_{2}$, and thus comparison of the $\mathrm{CO}_{2}$ uptake of the carbons at 0.15 bar with their $\mathrm{N}_{2}$ uptake at 0.85 bar gives a realistic estimation of selectivity for $\mathrm{CO}_{2}$. Selectivity analysis was determined using the ideal adsorbed solution theory (IAST) model, which is often used to estimate the relative uptake (or selectivity) of adsorbents for any two gases in a binary gas mixture. ${ }^{54}$ The selectivity for $\mathrm{CO}_{2}$ from the IAST model was derived from the following aquation; $\mathrm{S}=\mathrm{n}\left(\mathrm{CO}_{2}\right) \mathrm{p}\left(\mathrm{N}_{2}\right) /\left(\mathrm{n}\left(\mathrm{N}_{2}\right) \mathrm{p}\left(\mathrm{CO}_{2}\right)\right.$, where $\mathrm{S}$ is selectivity for $\mathrm{CO}_{2}, \mathrm{n}$ is uptake of $\mathrm{CO}_{2}$ and $\mathrm{N}_{2}$ in mmol $\mathrm{g}^{-1}$ at 0.15 bar and 0.85 bar, respectively, $\mathrm{p}\left(\mathrm{N}_{2}\right)$ is 0.85 and $\mathrm{p}\left(\mathrm{CO}_{2}\right)$ is 0.15$)$.

This comparison yielded high to very high selectivity factors (Table S5) of between 23 and 47, with the selectivity decreasing at higher levels of activation and therefore larger pore size. The selectivity of the directly synthesised samples was similar to that of analogous conventional samples. Overall, therefore, the present directly activated carbons are at the top end of carbon materials with respect to selectivity for $\mathrm{CO}_{2}$ uptake under post-combustion conditions. The direct synthesis does not compromise the selectivity for $\mathrm{CO}_{2}$ uptake. The data presented above demonstrates a clear advantage for our more direct and simple synthesis routes, which is generally desirable in materials synthesis. ${ }^{55-58}$ 


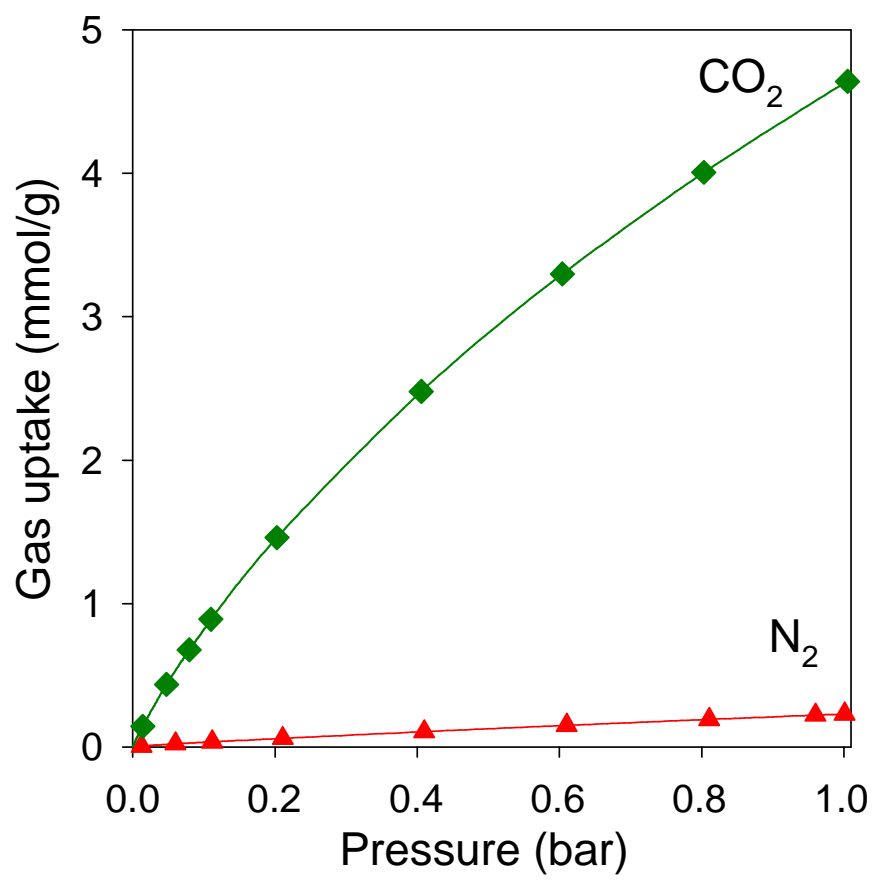

Figure 7. Comparison of $\mathrm{CO}_{2}$ and $\mathrm{N}_{2}$ uptake at room temperature for sample SD2700D. The $\mathrm{CO}_{2} / \mathrm{N}_{2}$ adsorption ratio is 21 at 1 bar.

We also determined the $\mathrm{CO}_{2}$ uptake of the carbons at $0{ }^{\circ} \mathrm{C}$ and pressure of up to $20 \mathrm{bar}$. The $\mathrm{CO}_{2}$ uptake isotherms are shown in Figure 8 (and Supporting Figure S15) and the storage capacity at various pressures $(0.15,1$ and 20 bar) are summarised in Table S6. The storage capacity at 1 bar (Figure $8 \mathrm{~B}$ ) ranges from $5.8 \mathrm{mmol} \mathrm{g}^{-1}$ to $7.3 \mathrm{mmol} \mathrm{g}^{-1}$, with samples prepared at $700{ }^{\circ} \mathrm{C}$ showing the highest capacity. The uptake of the directly activated samples is very similar to that of analogous conventionally activated carbons. The level of uptake at 1 bar of up to 7.3 mmol $\mathrm{g}^{-1}$ places the directly synthesised samples at the high end of what has been reported for carbons (Table S7) despite their being prepared via a simpler, cheaper and more direct route. ${ }^{9-}$ 12,34-48 At 20 bar (Figure $8 \mathrm{~A}$ ), the $\mathrm{CO}_{2}$ uptake correlates with the total surface area, and thus the directly activated samples generally have greater storage capacity (Table S6) with the highest uptake of $30.7 \mathrm{mmol} \mathrm{g}^{-1}$ exhibited by sample SD4800D (Supporting Figure S15). The CO2 uptake of the directly prepared samples is much higher than that of previously reported carbons (Table S7). 

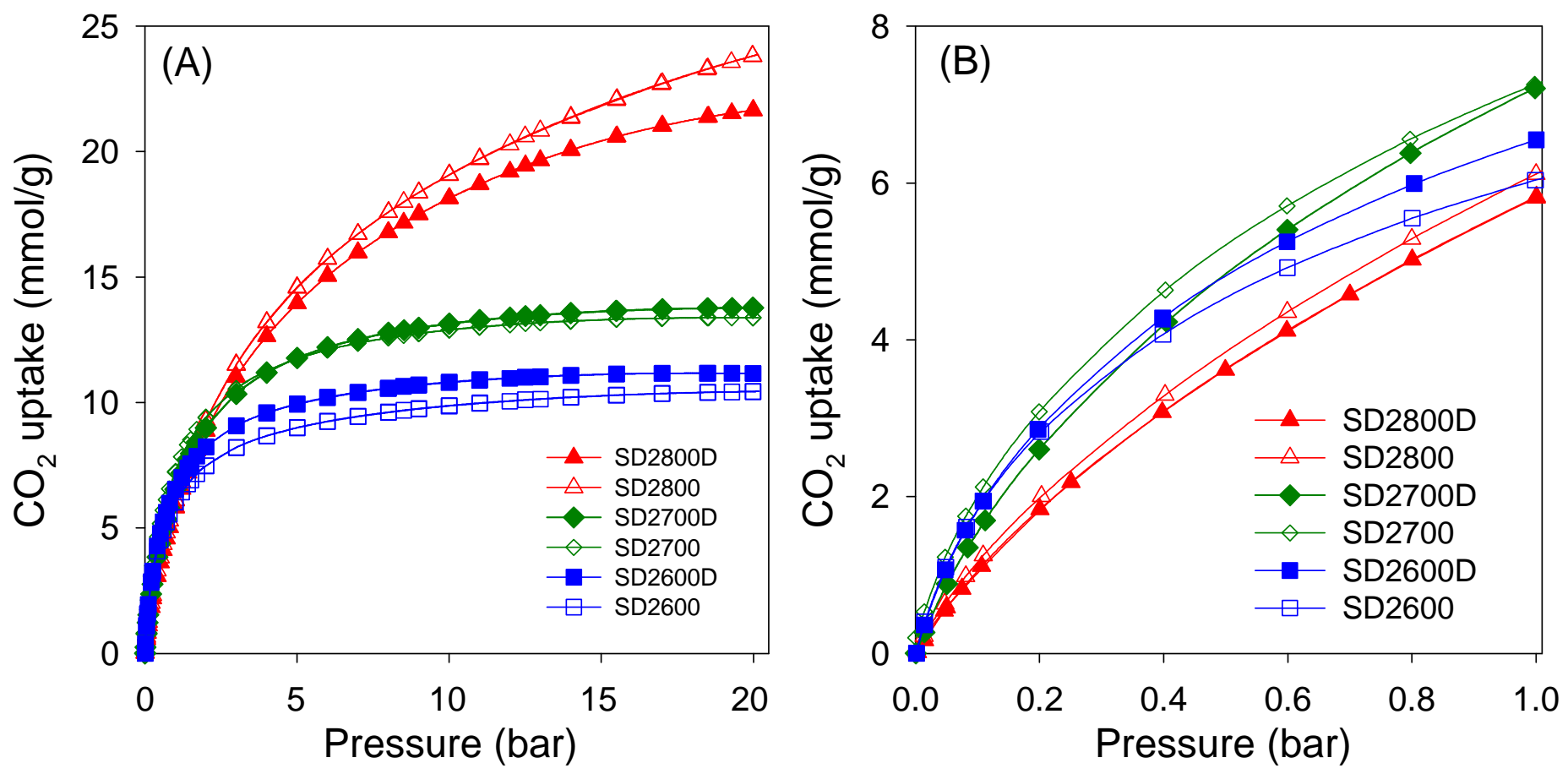

Figure 8. $\mathrm{CO}_{2}$ uptake isotherms at $0{ }^{\circ} \mathrm{C}$ and $0-20$ bar (A) and $0-1$ bar (B) for sawdustderived directly (SD2TD) and conventionally (SD2T) activated carbons. See experimental section for sample designation.

The $\mathrm{CO}_{2}$ uptake of carbons derived from the flowering plant Paeonia Lactiflora and seaweed Sargassum fusiforme were also assessed. The $\mathrm{CO}_{2}$ uptake of the directly activated carbons from Paeonia Lactiflora and seaweed Sargassum fusiforme were found to be comparable to those of conventionally prepared samples ((Table S2 and S3 and Supporting Figure S16 and S17). Overall, therefore, using the simpler, cheaper and more direct activation route generates carbons with $\mathrm{CO}_{2}$ uptake that is comparable or better than benchmark activated carbons that are prepared via routes that include the extra step of hydrothermal carbonisation or pyrolysis. 


\section{Conclusions}

Activated carbons were successfully produced from a range of biomass sources via direct activation that negates the need for hydrothermal carbonisation or pyrolysis. The direct carbonisation, with $\mathrm{KOH}$ as activating agent, generated activated carbon yields that are comparable or higher than those of conventional activation routes. A range of characterisation techniques confirmed that the directly activated carbons, whilst offering the advantage of simplicity, lower cost and a greener route, have properties that are similar to those prepared via conventional methods. In particular the textural properties and level of graphitic ordering was found to be similar to that of conventionally generated activated carbons. The nature of the direct activation, however, generated carbons with a monolith-like particle morphology. Depending on the activation conditions, the porosity of the directly activated carbons can be tailored to arise primarily from pore channels of size $5-7 \AA$, which favour post-combustion $\mathrm{CO}_{2}$ uptake and thus the carbons capture up to 1.3 and $4.6 \mathrm{mmol} \mathrm{g}^{-1}$ at 0.15 and $1 \mathrm{bar}$, respectively, and $25^{\circ} \mathrm{C}$. At higher levels of activation, directly activated carbons with greater proportion of larger micropores (10 - $20 \AA$ pores) and small mesopores $(20-30 \AA$ pores $)$ can be generated that have optimized $\mathrm{CO}_{2}$ uptake at moderate to high pressure, for example up to $22 \mathrm{mmol} \mathrm{g}^{-1}$ at 20 bar and $25^{\circ} \mathrm{C}$ or $31 \mathrm{mmol} \mathrm{g}^{-1}$ at 20 bar and $0{ }^{\circ} \mathrm{C}$.

\section{Supporting Information}

seven tables with porosity and $\mathrm{CO}_{2}$ uptake for carbons derived from sawdust, the flowering plant Paeonia Lactiflora or seaweed (Sargassum fusiforme), and comparative data from previous 
reports. Seventeen additional figures; TGA curves, XRD patterns, nitrogen sorption isotherms and pore size distribution curves, SEM images, and gravimetric $\mathrm{CO}_{2}$ uptake isotherms for carbons derived from sawdust, the flowering plant Paeonia Lactiflora or seaweed (Sargassum fusiforme).

\section{Acknowledgements}

We thank Dr. Graham Rance for help with Raman spectroscopy and the Nanoscale and Microscale Research Centre (NMRC) at the University of Nottingham for assistance with SEM and TEM analysis. We thank the government of the Kingdom of Saudi Arabia for funding a PhD studentship for Norah Balahmar, and the government of Iraq for funding a PhD studentship for Abdul Salam Al-Jumialy.

\section{References}

1. J. A. Turner, Science 1999, 285, 687.

2. L. Schlapbach and A. Züttel, Nature 2001, 414, 353.

3. C. Liu, F. Li, L-P. Ma and H-M. Cheng, Adv. Mater. 2010, 22, E28-E62

4. M. Sevilla and R. Mokaya, Energy Environ. Sci., 2014, 7, 1250.

5. F. Çeçen and Ö. Aktas, Activated Carbon for Water and Wastewater treatment, 2011, Ed. Wiley-VCH, Weinheim.

6. Y. X. Xia, Z. X. Yang and Y. Zhu, J. Mater. Chem. A, 2013, 19365.

7. J. C. Wang and S. Kaskel, J. Mater. Chem., 2012, 22, 23710.

8. L. Wei and G. Yushin, Nano Energy, 2012, 1, 552.

9. M. Sevilla, A. B. Fuertes and R. Mokaya, Energy Environ. Sci., 2011, 3, 1400.

10. H. M. Coromina, D. A. Walsh and R. Mokaya, J. Mater. Chem. A 2016, 4, 280.

11. W. Sangchoom and R. Mokaya, ACS Sust. Chem. Eng., 2015, 3, 1658.

12. N. Balahmar, A. C. Mitchell, and R. Mokaya, Adv. Energy Mater., 2015, 5, 1500867

13. C. Robertson and R. Mokaya, Micropor. Mesopor. Mater., 2013, 179, 151.

14. M. Sevilla, W. Sangchoom, N. Balahmar, A. B. Fuertes and R. Mokaya, ACS Sust. Chem. Eng., 2016, 4, 4710. 
15. L. Wei, M. Sevilla, A. B. Fuertes, R. Mokaya and G. Yushin, Adv. Energy Mater., 2011, $1,356$.

16. B. Hu, K. Wang, L. Wu, S. H. Yu, M. Antonietti and M. M. Titirici, Adv. Mater., 2010, 22, 813 .

17. M. M. Titirici and M. Antonietti, Chem. Soc. Rev., 2010, 39, 103.

18. M. M. Titirici, R. J. White, C. Falco, M. Sevilla, Energy Environ. Sci., 2012, 5, 6796.

19. M. Sevilla and A. B. Fuertes, Carbon, 2009, 47, 2281.

20. J. A. Libra, K. S. Ro, C. Kammann, A. Funke, N. D. Berge, Y. Neubauer, M. M. Titirici, C. Fühner, O. Bens, J. Kern and K. H. Emmerich, Biofuels, 2011, 2, 89.

21. F. Shafizadeh, J. Anal. Appl. Pyrolysis, 1982, 3, 283.

22. A. Demirbas and G. Arin, Energy Sources, 2002, 24, 471.

23. M. X. Fang, D. K. Shen, Y. X. Li, C. J. Yu, Z. Y. Luo, K. F. Cen, J. Anal. Appl. Pyrolysis, 2006, 77, 22.

24. A.V. Bridgwater, D. Meier and D. Radlein, Org. Geochem., 1999, 30, 1479.

25. E. Sermyagina, J. Saari, J. Kaikko and E. Vakkilainen, J. Anal. Appl. Pyrolysis, 2015, $113,551$.

26. J. G. Lynam, M. T. Reza, W. Yan, V. R. Vásquez and C. J. Coronella, Biomass Conv. Bioref., 2015, 5, 173.

27. Z. Liu, A. Quek, S. K. Hoekman, R. Balasubramanian, Fuel, 2013, 103, 943.

28. M. Sevilla, R. Mokaya and A. B. Fuertes, Energy Environ. Sci., 2011, 4, 2930.

29. B. Adeniran and R. Mokaya, Nano Energy, 2015, 16, 173.

30. M. Sevilla, A. B. Fuertes and R. Mokaya, Int. J. Hydrogen Energy, 2011, 36, 15658.

31. E. Haffner-Staton, N. Balahmar and R. Mokaya, J. Mater. Chem. A 2016, 4, 13324.

32. A. C. Ferrari and J. Robertson, Phys. Rev. B, 2000, 61, 14095.

33. M. Sevilla, J. A. Maciá-Agulló and A. B. Fuertes, Biomass and Bioenergy, 2011, 35, 3152 .

34. B. Adeniran and R. Mokaya, J. Mater. Chem. A, 2015, 3, 5148.

35. A. Almasoudi and R. Mokaya, J. Mater. Chem. A, 2014, 2, 10960.

36. Z. Zhang, J. Zhou, W. Xing, Q. Xue, Z. Yan, S. Zhuo and S. Z. Qiao, Phys. Chem. Chem. Phys., 2013, 15, 2523.

37. N. P. Wickramaratne and M. Jaroniec, ACS Appl. Mater. Interfaces, 2013, 5, 1849.

38. N. P. Wickramaratne and M. Jaroniec, J. Mater. Chem. A., 2013, 1, 112.

39. B. Adeniran and R. Mokaya, Chem. Mater. 2016, 28, 994. 
40. M. Nandi, K. Okada, A. Dutta, A. Bhaumik, J. Maruyama, D. Derksa and H. Uyama, Chem. Commun., 2012, 48, 10283.

41. B. Adeniran, E. Masika and R. Mokaya, J. Mater. Chem. A, 2014, 2, 14696.

42. X. Fan, L. Zhang, G. Zhang, Z. Shu and J. Shi, Carbon, 2013, 61, 423.

43. Y. D. Xia, R. Mokaya, G. S. Walker and Y. Q. Zhu, Adv. Energy Mater., 2011, 1, 678.

44. A. Almasoudi and R. Mokaya. J. Mater. Chem., 2012, 22, 146.

45. D. Lee, C. Zhang, C. Wei, B. L. Ashfeld and H. Gao, J. Mater. Chem. A, 2013, 1, 14862.

46. J. Silvestre-Albero, A. Wahby, A. Sepulveda-Escribano, M. Martinez-Escandell, K. Kaneko and F. Rodriguez-Reinoso, Chem. Commun., 2011, 47, 6840.

47. A. Wahby, J. M. Ramos-Fernandez, M. Martnez-Escandell, A. Sepulveda-Escribano, J. Silvestre-Albero and F. Rodriguez-Reinoso, ChemSusChem, 2010, 3, 974.

48. G. Srinivas, J. Burress and T. Yildirim, Energy Environ. Sci., 2012, 5, 6453.

49. J. D. Figueroa, T. Fout, S. Plasynski, H. McIlvried and R. D. Srivastava, Int. J. Greenhouse Gas Control, 2008, $2,9$.

50. Z. Zhang, K. Wang, J. D. Atkinson, X. Yan, X. Li, M. J. Rood and Z. Yan, J. Hazard. Mater., 2012, 229-230, 183.

51. M. Sevilla and A. B. Fuertes, Energy Environ. Sci., 2011, 4, 1765.

52. M. Sevilla, P. Valle-Vigon and A. B. Fuertes, Adv. Funct. Mater., 2011, 21, 2781.

53. C. Chen, J. Kim and W. S. Ahn, Fuel, 2012, 95, 360.

54. A. L. Myers and J. M. Prausnitz, AlChE J., 1965, 11, 121.

55. Y. Xia, R. Mokaya, D. M. Grant and G. S. Walker, Carbon, 2011, 49, 844.

56. R. Mokaya, Chem. Commun. 2001, 633.

57. R. Mokaya and W. Jones, Chem. Commun. 1996, 983.

58. R. Mokaya, W. Jones, S. Moreno and G. Poncelet, Catalysis Lett.. 1997, 49, 87. 


\section{Graphical Abstract}

The direct conversion of biomass to activated carbons in a simple and lower cost one step process, which negates the need for hydrothermal carbonisation or pyrolysis, generates activated carbon with properties and $\mathrm{CO}_{2}$ uptake comparable or superior to conventionally prepared activated carbons.

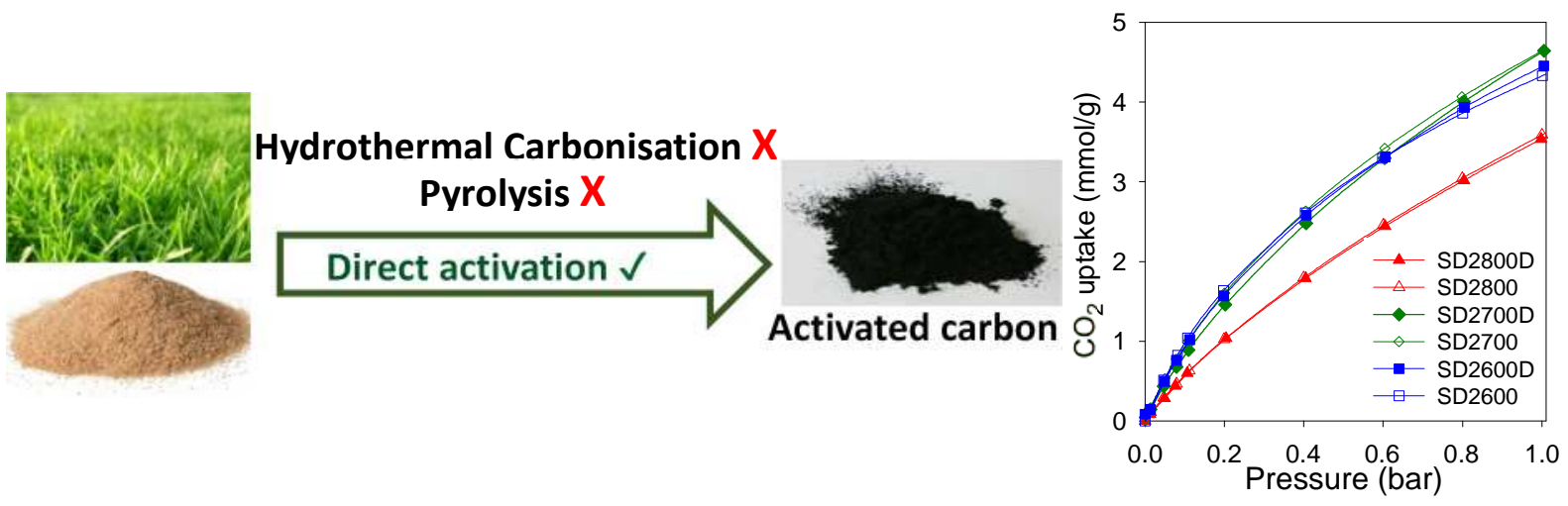


Supporting Information

\section{Biomass to porous carbon in one step: Directly activated biomass for high performance $\mathrm{CO}_{2}$ storage}

Norah Balahmar, Abdul S. Al-Jumialy and Robert Mokaya*

University of Nottingham, University Park, Nottingham NG7 2RD, U. K.

E-mail:r.mokaya@nottingham.ac.uk (R.Mokaya) 
Table S1. The ratio of peak intensity of the D-peak to G-peak $\left(\mathrm{I}_{\mathrm{D}} / \mathrm{I}_{\mathrm{G}}\right)$ of directly activated or conventionally activated carbons derived from sawdust biomass.

\begin{tabular}{ll}
\hline Sample & $\mathrm{I}_{\mathrm{D}} / \mathrm{I}_{\mathrm{G}}$ \\
\hline $\mathrm{SD} 2600 \mathrm{D}$ & 0.78 \\
$\mathrm{SD} 2600$ & 0.79 \\
$\mathrm{SD} 2700 \mathrm{D}$ & 0.83 \\
$\mathrm{SD} 2700$ & 0.81 \\
$\mathrm{SD} 2800 \mathrm{D}$ & 0.84 \\
$\mathrm{SD} 2800$ & 0.84 \\
$\mathrm{SD} 4800 \mathrm{D}$ & 0.87 \\
$\mathrm{SD} 4800$ & 0.86 \\
\hline
\end{tabular}


Table S2. Textural properties and $\mathrm{CO}_{2}$ uptake of directly activated or conventionally activated carbons derived from Paeonia Lactiflora biomass

\begin{tabular}{llllllr}
\hline Sample & $\begin{array}{l}\text { Surface area } \\
\left(\mathrm{m}^{2} \mathrm{~g}^{-1}\right)\end{array}$ & $\begin{array}{l}\text { Pore volume }^{\mathrm{b}} \\
\left(\mathrm{cm}^{3} \mathrm{~g}^{-1}\right)\end{array}$ & $\begin{array}{l}\text { Pore size }^{\mathrm{c}} \\
(\AA)\end{array}$ & \multicolumn{2}{l}{$\begin{array}{l}\mathrm{CO}_{2} \text { uptake }^{\mathrm{d}} \\
\left(\mathrm{mmol} \mathrm{g}^{-1}\right)\end{array}$} & \\
\hline PLF2800D & $2349(1915)$ & $1.48(0.86)$ & $8.5 / 11 / 20$ & 0.9 & 3.9 & 17 bar \\
PLF2800 & $1908(1471)$ & $1.20(0.67)$ & $8 / 11 / 20$ & 0.6 & 2.8 & 16.0 \\
\hline
\end{tabular}

The values in the parenthesis refer to: ${ }^{a}$ micropore surface area and ${ }^{\mathbf{b}}$ micropore volume. ${ }^{\mathbf{c}}$ Pore size distribution maxima obtained from NLDFT analysis. ${ }^{\mathrm{d}} \mathrm{CO}_{2}$ uptake at $25{ }^{\circ} \mathrm{C}$ and various pressures (i.e., 0.15 bar, 1 bar and 20 bar). 
Table S3. Textural properties and $\mathrm{CO}_{2}$ uptake of directly activated or conventionally activated carbons derived from seaweed (Sargassum fusiforme).

\begin{tabular}{|c|c|c|c|c|c|c|}
\hline \multirow[t]{2}{*}{ Sample } & \multirow[t]{2}{*}{$\begin{array}{l}\text { Surface area } \\
\left(\mathrm{m}^{2} \mathrm{~g}^{-1}\right)\end{array}$} & \multirow[t]{2}{*}{$\begin{array}{l}\text { Pore volume } \\
\left(\mathrm{cm}^{3} \mathrm{~g}^{-1}\right)\end{array}$} & \multirow[t]{2}{*}{$\begin{array}{l}\text { Pore size }{ }^{c} \\
(\AA)\end{array}$} & \multicolumn{3}{|c|}{$\begin{array}{l}\mathrm{CO}_{2} \text { uptake }^{\mathrm{d}} \\
\left(\mathrm{mmol} \mathrm{g}^{-1}\right)\end{array}$} \\
\hline & & & & 0.15 bar & $1 \mathrm{bar}$ & 20 bar \\
\hline SW2600D & $976(692)$ & $0.50(0.27)$ & $6 / 8 / 12$ & 1.0 & 2.7 & 8.0 \\
\hline SW2600 & 1034 (923) & $0.46(0.37)$ & $6 / 8 / 12$ & 1.3 & 3.8 & 7.8 \\
\hline SW2700D & $1986(1350)$ & $0.96(0.53)$ & $6 / 8 / 12 / 19$ & 0.8 & 2.6 & 11.4 \\
\hline SW2700 & $1624(1442)$ & $0.73(0.58)$ & $6 / 8 / 9 / 12$ & 1.2 & 4.2 & 12.4 \\
\hline SW2800D & 3095 (1009) & $1.68(0.39)$ & $6 / 8 / 12 / 24$ & 0.5 & 2.2 & 13.5 \\
\hline SW2800 & 2085 (1667) & $0.93(0.66)$ & $6 / 8 / 12 / 19$ & 0.8 & 3.4 & 15.5 \\
\hline
\end{tabular}


Table S4. $\mathrm{CO}_{2}$ uptake of various porous carbons at $25^{\circ} \mathrm{C}$ and 0.15 bar or 1 bar (Table adapted from ref. 41)

\begin{tabular}{llll}
\hline & \multicolumn{2}{l}{$\mathrm{CO}_{2}$ uptake $(\mathrm{mmol} / \mathrm{g})$} & Reference \\
& 1 bar & $0.15 \mathrm{bar}$ & \\
\hline Sawdust-derived activated carbon & 4.8 & 1.2 & 1 \\
KOH-activated templated carbons & 3.4 & $\sim 1.0$ & 2 \\
Hierarchical porous carbon (HPC) & 3.0 & $\sim 0.9$ & 3 \\
Petroleum pitch-derived activated carbon & 4.55 & $\sim 1.0$ & 4 \\
Activated carbon spheres & 4.55 & $\sim 1.1$ & 5 \\
Phenolic resin activated carbon spheres & 4.5 & $\sim 1.2$ & 6 \\
Poly(benzoxazine-co-resol)-derived carbon & 3.3 & 1.0 & 7 \\
Fungi-derived activated carbon & 3.5 & $\sim 1.0$ & 8 \\
Chitosan-derived activated carbon & 3.86 & $\sim 1.1$ & 9 \\
Polypyrrole derived activated carbon & 3.9 & $\sim 1.0$ & 10 \\
Soya bean derived N-doped activated carbon & 4.24 & 1.2 & 11 \\
N-doped ZTCs & 4.4 & $\sim 1.0$ & 12 \\
Activated templated N-doped carbon & 4.5 & 1.4 & 13 \\
Polyaniline derived activated carbon & 4.3 & 1.38 & 14 \\
N-doped activated carbon monoliths & 5.14 & 1.25 & 15 \\
Activated N-doped carbon & 3.2 & 1.5 & 16 \\
Activated hierarchical N-doped carbon & 4.8 & 1.4 & 17 \\
Activated N-doped carbon from algae & 4.5 & $\sim 1.1$ & 18 \\
\hline
\end{tabular}

1. M. Sevilla and A. B. Fuertes, Energy Environ. Sci., 2011, 4, 1765.

2. M. Sevilla and A. B. Fuertes, J. Colloid Interface Sci., 2012, 366, 147.

3. G. Srinivas, V. Krungleviciute, Z. X. Guo and T. Yildirim, Energy Environ. Sci., 2014, 7, 335.

4. J. Silvestre-Albero, A. Wahby, A. Sepulveda-Escribano, M. Martinez-Escandell, K. Kaneko and F. Rodriguez-Reinoso, Chem. Commun., 2011, 47, 6840.

5. N. P. Wickramaratne and M. Jaroniec, ACS Appl. Mater. Interfaces, 2013, 5, 1849.

6. N. P. Wickramaratne and M. Jaroniec, J. Mater. Chem. A, 2013, 1,112.

7. G. P. Hao, W. C. Li, D. Qian, G. H. Wang, W. P. Zhang, T. Zhang, A. Q. Wang, F. Schuth, H. J. Bongard and A. H. Lu, J. Am. Chem. Soc., 2011, 133, 11378.

8. J. Wang, A. Heerwig, M. R. Lohe, M. Oschatz, L. Borchardt and Stefan Kaskel, J. Mater. Chem., 2012, 22, 13911.

9. X. Fan, L. Zhang, G. Zhang, Z. Shu, J. Shi, Carbon, 2013, 61, 423.

10. M. Sevilla, P. Valle-Vigon and A. B. Fuertes, Adv. Funct. Mater., 2011, 21, 2781.

11. W. Xing, C. Liu, Z. Y. Zhou, L. Zhang, J. Zhou, S. P. Zhuo, Z. F. Yan, H. Gao, G. Q. Wang and S. Z. Qiao, Energy Environ. Sci., 2012, 5, 7323.

12. Y. D. Xia, R. Mokaya, G. S. Walker and Y. Q. Zhu, Adv. Energy Mater., 2011, 1, 678.

13. Y. Zhao, L. Zhao, K. X. Yao, Y. Yang, Q. Zhang and Y. Han, J. Mater. Chem., 2012, 22, 19726.

14. Z. Zhang, J. Zhou, W. Xing, Q. Xue, Z. Yan, S. Zhuo and S. Z. Qiao, Phys.Chem. Chem. Phys., 2013, 15, 2523

15. M. Nandi, K. Okada, A. Dutta, A. Bhaumik, J. Maruyama, D. Derks and Hiroshi Uyama, Chem. Commun., $2012,48,10283$.

16. M. Saleh, J. N. Tiwari, K. C. Kemp, M. Yousuf and K. S. Kim, Environ. Sci. Technol., 2013, 47, 5467.

17. D. Lee, C. Zhang, C. Wei, B. L. Ashfeld and H. Gao, J. Mater. Chem. A, 2013, 1, 14862.

18. M. Sevilla, C. Falco, M. M. Titirici and A. B. Fuertes, RSC Advances, 2012, 2, 12792. 
Table S5. Selectivity (S) for $\mathrm{CO}_{2}$ of directly activated or conventionally activated carbons derived from sawdust biomass calculated using the IAST model.

\begin{tabular}{lc}
\hline Sample & IAST selectivity (S) \\
\hline SD2600D & 46 \\
SD2600 & 47 \\
SD2700D & 42 \\
SD2700 & 41 \\
SD2800D & 30 \\
SD2800 & 29 \\
SD4800D & 23 \\
SD4800 & 25 \\
\hline
\end{tabular}

Selectivity (S) was calculated according to the equation; $\mathrm{S}=\mathrm{n}\left(\mathrm{CO}_{2}\right) \mathrm{p}\left(\mathrm{N}_{2}\right) /\left(\mathrm{n}\left(\mathrm{N}_{2}\right) \mathrm{p}\left(\mathrm{CO}_{2}\right)\right.$, where $\mathrm{S}$ is selectivity for $\mathrm{CO}_{2}, \mathrm{n}$ is uptake of $\mathrm{CO}_{2}$ or $\mathrm{N}_{2}$ in $\mathrm{mmol} \mathrm{g}^{-1}$ at 0.15 bar and 0.85 bar, respectively, $\mathrm{p}\left(\mathrm{N}_{2}\right)$ is 0.85 and $\mathrm{p}\left(\mathrm{CO}_{2}\right)$ is 0.15$)$. 
Table S6. $\mathrm{CO}_{2}$ uptake at $0{ }^{\circ} \mathrm{C}$ of directly activated or conventionally activated carbons derived from sawdust biomass

\begin{tabular}{llll}
\hline Sample & \multicolumn{2}{l}{$\begin{array}{l}\mathrm{CO}_{2} \text { uptake }^{\mathrm{a}} \\
\left(\mathrm{mmol} \mathrm{g}^{-1}\right)\end{array}$} \\
& 0.15 bar & 1 bar & 20 bar \\
\hline SD2600D & 2.4 & 6.1 & 10.4 \\
SD2600 & 2.5 & 6.6 & 11.2 \\
SD2700D & 2.6 & 7.3 & 13.4 \\
SD2700 & 2.2 & 6.8 & 13.8 \\
SD2800D & 1.7 & 6.1 & 23.8 \\
SD2800 & 1.5 & 5.8 & 21.7 \\
SD4800D & 1.1 & 4.8 & 30.3 \\
SD4800 & 0.9 & 4.1 & 30.7 \\
\hline${ }^{\mathrm{a} C O} 2$ uptake at $0{ }^{\circ} \mathrm{C}$ and various pressures (i.e., 0.15 bar, 1 bar and 20 bar).
\end{tabular}


Table S7. $\mathrm{CO}_{2}$ uptake at $0{ }^{\circ} \mathrm{C}$ and 1 bar of various carbons compared to study carbons.

\begin{tabular}{lll}
\hline Sample & $\begin{array}{l}\mathrm{CO}_{2} \text { uptake }^{\mathrm{d}} \\
\left(\mathrm{mmol} \mathrm{g}^{-1}\right) \text { at } 1 \mathrm{bar}\end{array}$ & Reference \\
\hline SD2600D & 6.1 & This work \\
SD2600 & 6.6 & This work \\
SD2700D & 7.3 & This work \\
SD2700 & 6.8 & This work \\
SD2800D & 6.1 & This work \\
SD2800 & 5.8 & This work \\
SD4800D & 4.8 & This work \\
SD4800 & 4.1 & This work \\
N-Doped microporous carbon & 2.7 & 1 \\
Microporous carbon & 2.3 & 2 \\
Microporous organic polymer & 3.5 & 3 \\
Covalent organic framework & 4.0 & 4 \\
Hollow octahedral carbon cage & 4.0 & 5 \\
Hierarchically porous carbon & 4.6 & 6 \\
N-Doped carbon monolith & 4.2 & 7 \\
Porous carbon sheets & 4.3 & 8 \\
NPCNS carbon & 4.4 & 9 \\
\hline
\end{tabular}

1. J. Wang, I. Senkovska, M. Oschatz, M. R. Lohe, L. Borchardt, A. Heerwig, Q. Liu and S. Kaskel, ACS Appl. Mater. Interfaces, 2013, 5, 3160.

2. D. L. Sivadas, R. Narasimman, R. Rajeev, K. Prabhakaran and K. N. Ninan, J. Mater. Chem. A, 2015, 3, 16213.

3. R. Du, N. Zhang, H. Xu, N. Mao, W. Duan, J. Wang, Q. Zhao, Z. Liu and J. Zhang, Adv. Mater., 2014, 26, 8053.

4. N. Huang, X. Chen, R. Krishna and D. Jiang, Angew. Chem., Int. Ed., 2015, 54, 2986.

5. A. Aijaz, J.-K. Sun, P. Pachfule, T. Uchida and Q. Xu, Chem. Commun., 2015, 51, 13945.

6. S. J. Yang, M. Antonietti and N. Fechler, J. Am. Chem. Soc., 2015, 137, 8269.

7. N. López-Salas, M. C. Gutiérrez, C. O. Ania, J. L. G. Fierro, M. L. Ferrer and F. del Monte, J. Mater. Chem. A, 2014, 2, 17387.

8. G.-P. Hao, Z.-Y. Jin, Q. Sun, X.-Q. Zhang, J.-T. Zhang and A.-H. Lu, Energy Environ. Sci., 2013, 6, 3740.

9. J. Gong, H. Lin, M. Antonietti and J. Yuan, J. Mater. Chem. A, 2016, 4, 7313. 

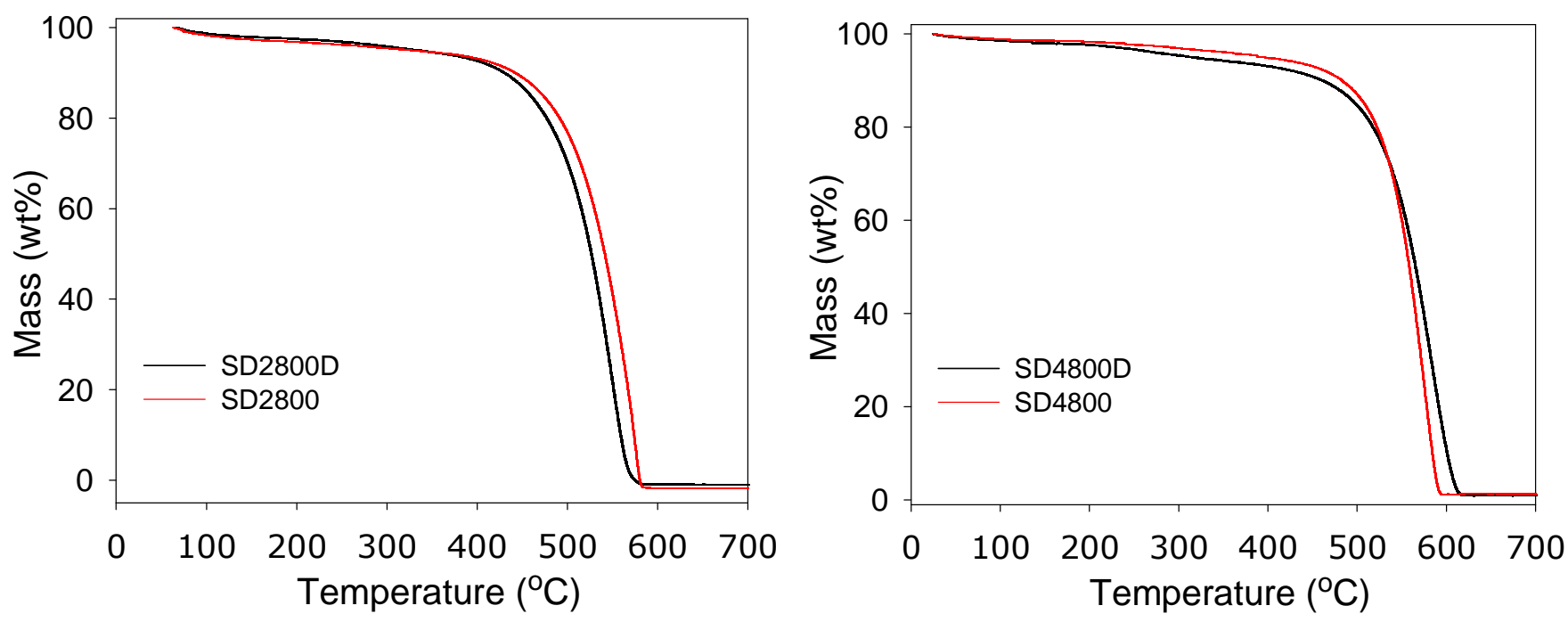

Supporting Figure S1. Thermogravimetric analysis (TGA) curve of sawdust-derived directly activated (SDxTD) or conventionally generated, via hydrothermal carbonisation, (SDxT) carbons. 

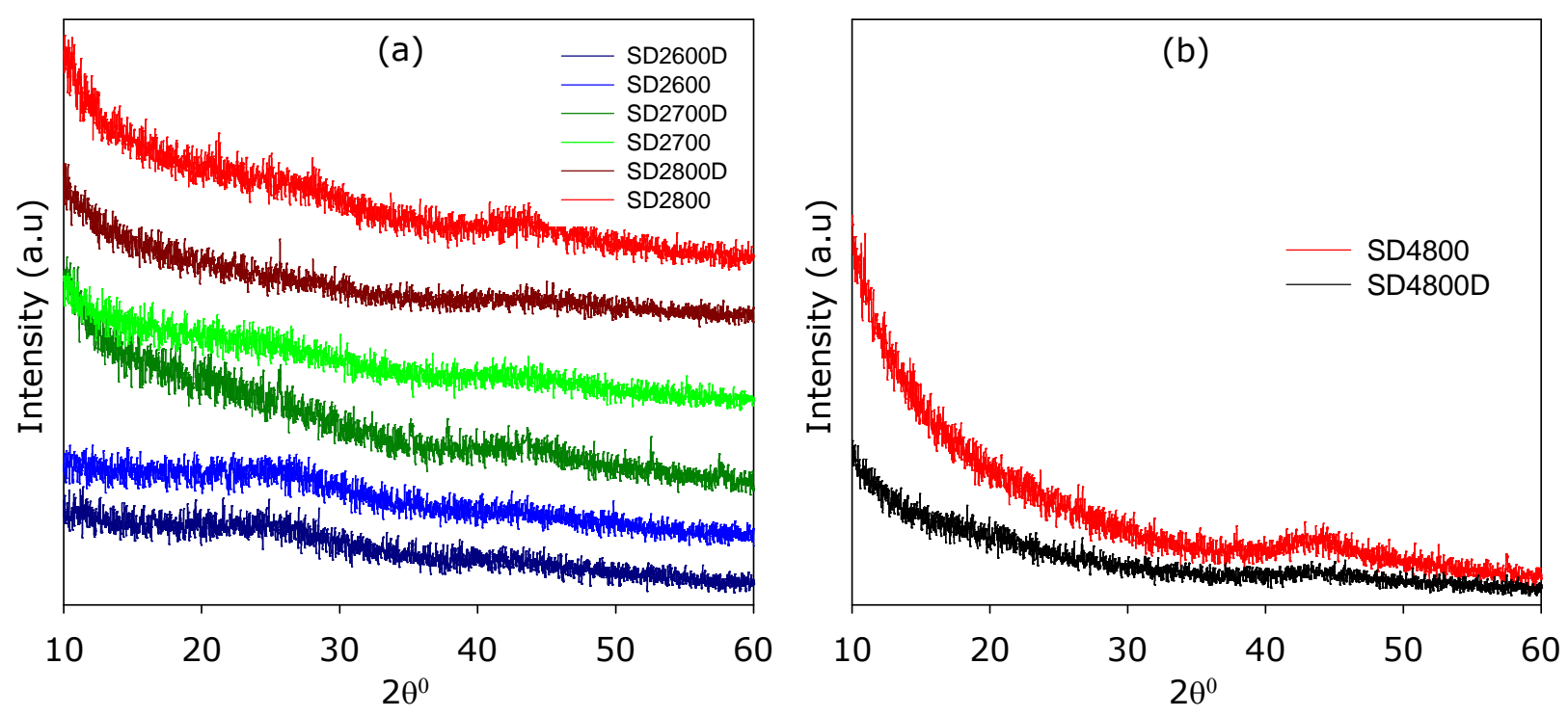

Supporting Figure S2. Powder XRD patterns of sawdust-derived directly activated (SDxTD) or conventionally generated, via hydrothermal carbonisation, (SDxT) carbons prepared at $\mathrm{KOH} /$ carbon ratio of (a) 2 or (b) 4. 

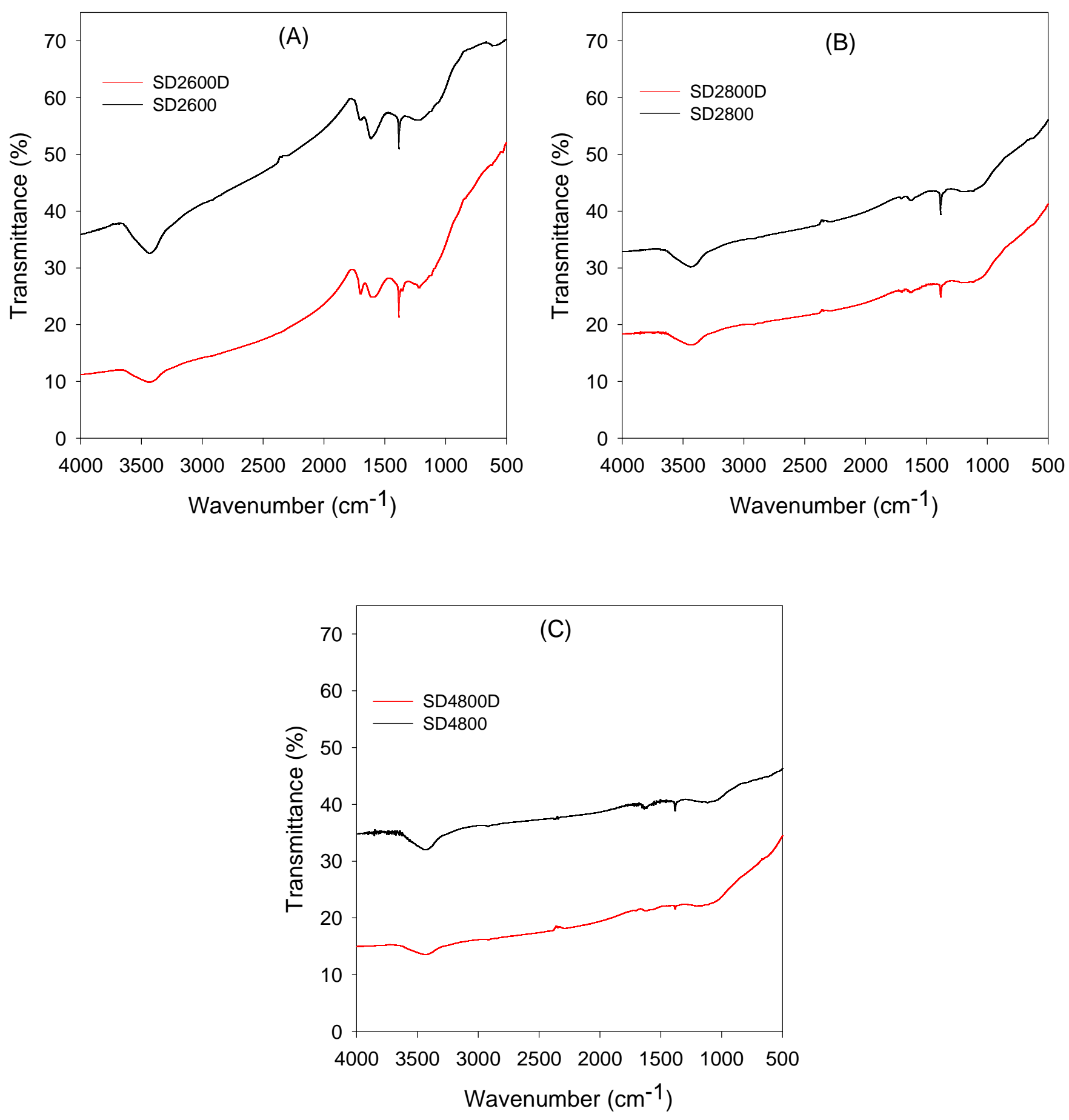

Supporting Figure S3. IR spectra of sawdust-derived directly activated (SD2TD) and conventionally generated (SD2T) carbons prepared at $\mathrm{KOH} /$ carbon ratio of 2 (A and $\mathrm{B}$ ) or 4 (C) and various temperatures; (A) $600{ }^{\circ} \mathrm{C}$, (B and C) $800{ }^{\circ} \mathrm{C}$. 

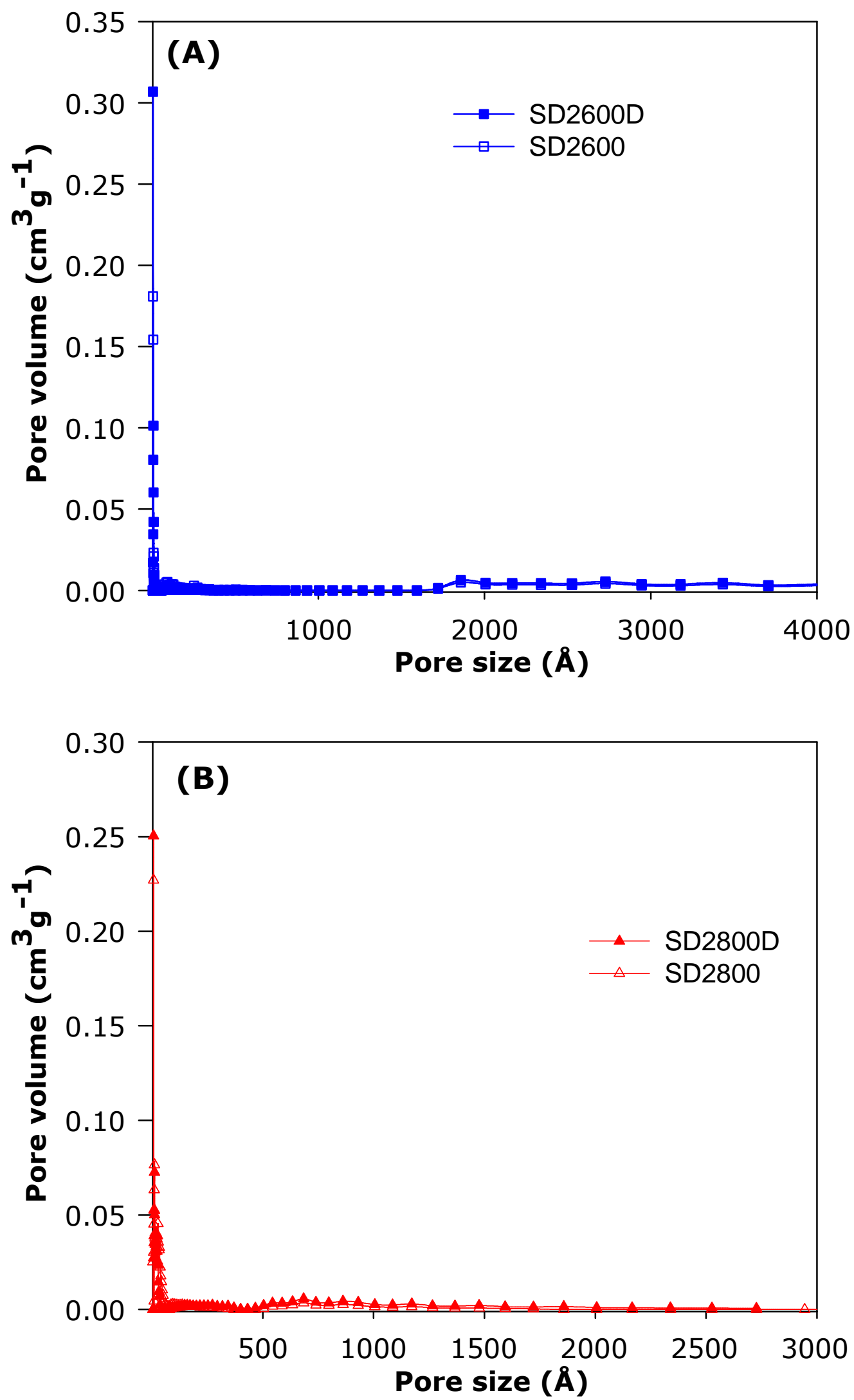

Supporting Figure S4. Pore size distribution of sawdust-derived directly activated (SD2TD) and conventionally generated (SD2T) carbons prepared at $\mathrm{KOH} /$ carbon ratio of 2 and (A) $600{ }^{\circ} \mathrm{C}$ or (B) $800{ }^{\circ} \mathrm{C}$. 

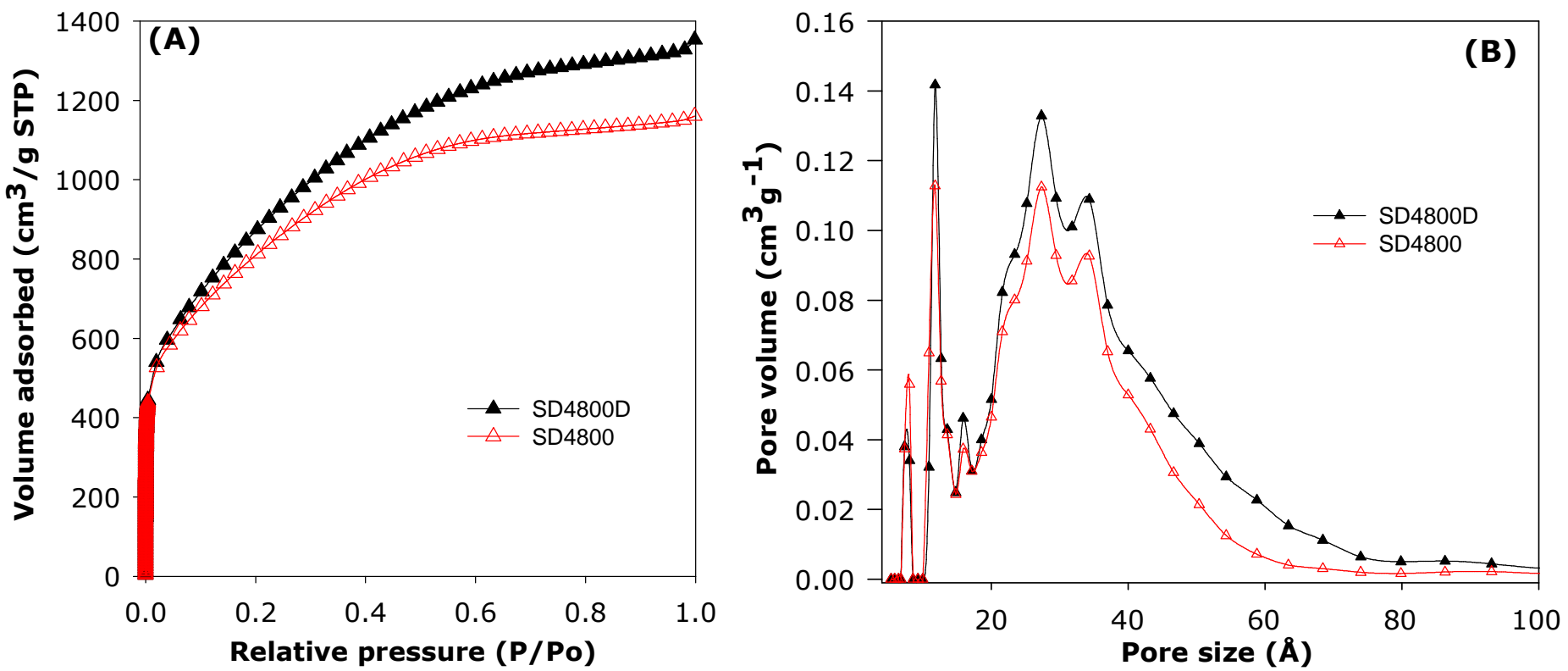

Supporting Figure S5. Nitrogen sorption isotherms (A) and corresponding pore size distribution curves (B) of sawdust-derived directly activated (SD4800D) or conventionally generated, via hydrothermal carbonisation, (SD4800) carbons prepared at $800{ }^{\circ} \mathrm{C}$ and $\mathrm{KOH} /$ carbon ratio of 4 . 


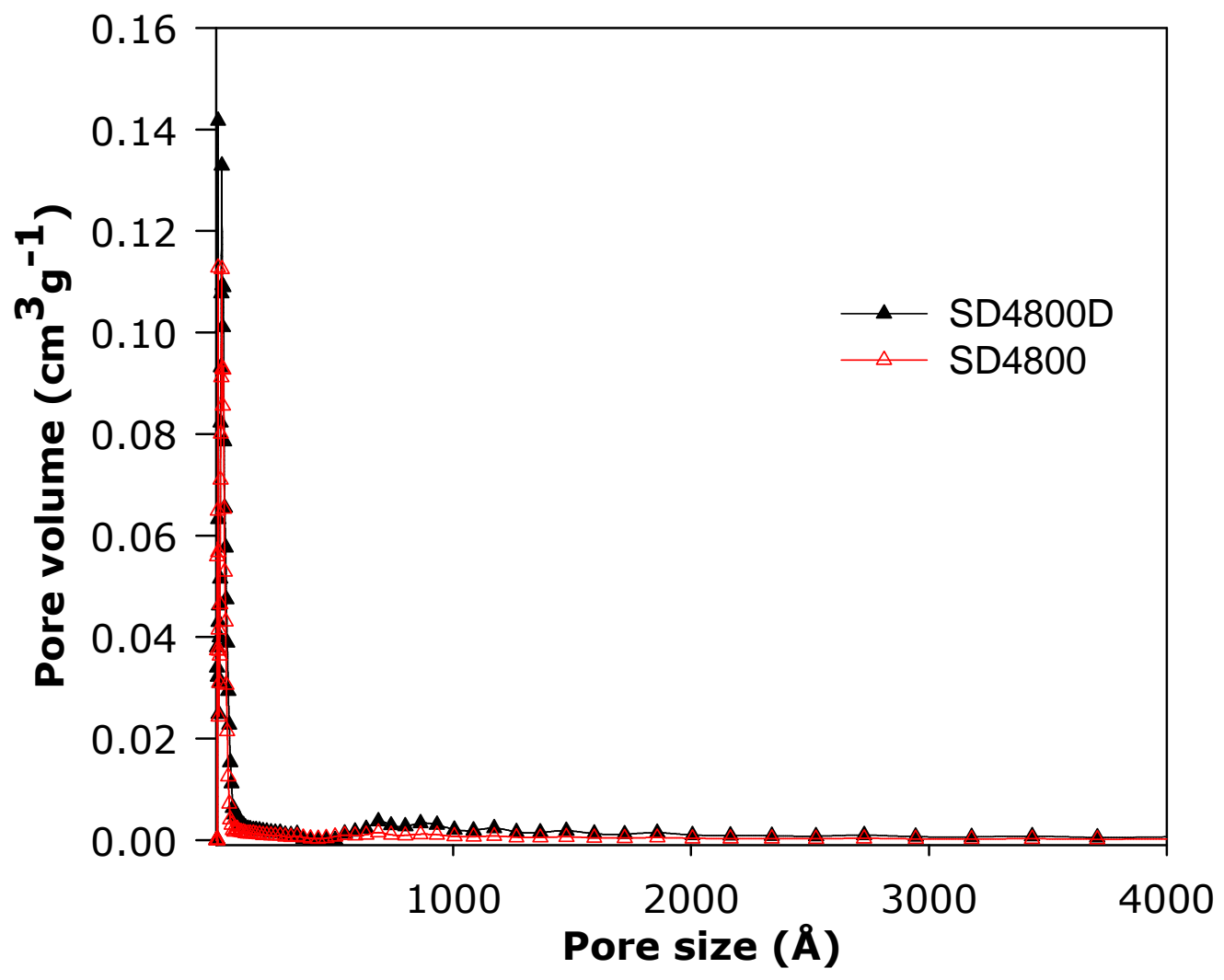

Supporting Figure S6. Pore size distribution curves of sawdust-derived directly activated (SD4800D) or conventionally generated, via hydrothermal carbonisation, (SD4800) carbons prepared at $800^{\circ} \mathrm{C}$ and $\mathrm{KOH} /$ carbon ratio of 4 . 

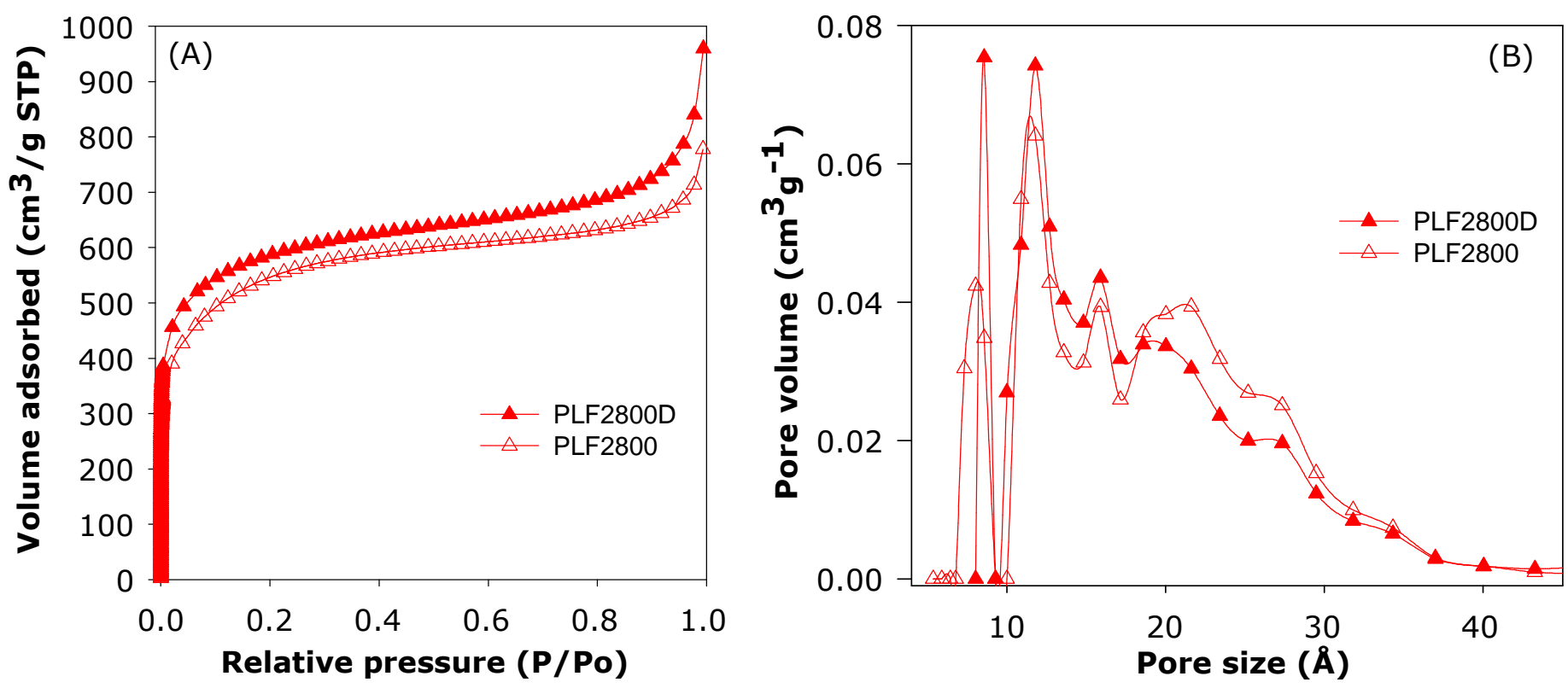

Supporting Figure S7. Nitrogen sorption isotherms (A) and corresponding pore size distribution curves (B) of directly activated (PLF2800D) or conventionally generated, via hydrothermal carbonisation, (PLF2800) carbons derived from the flowering plant Paeonia Lactiflora. The carbons were prepared at $800{ }^{\circ} \mathrm{C}$ and $\mathrm{KOH} /$ carbon ratio of 2 . 


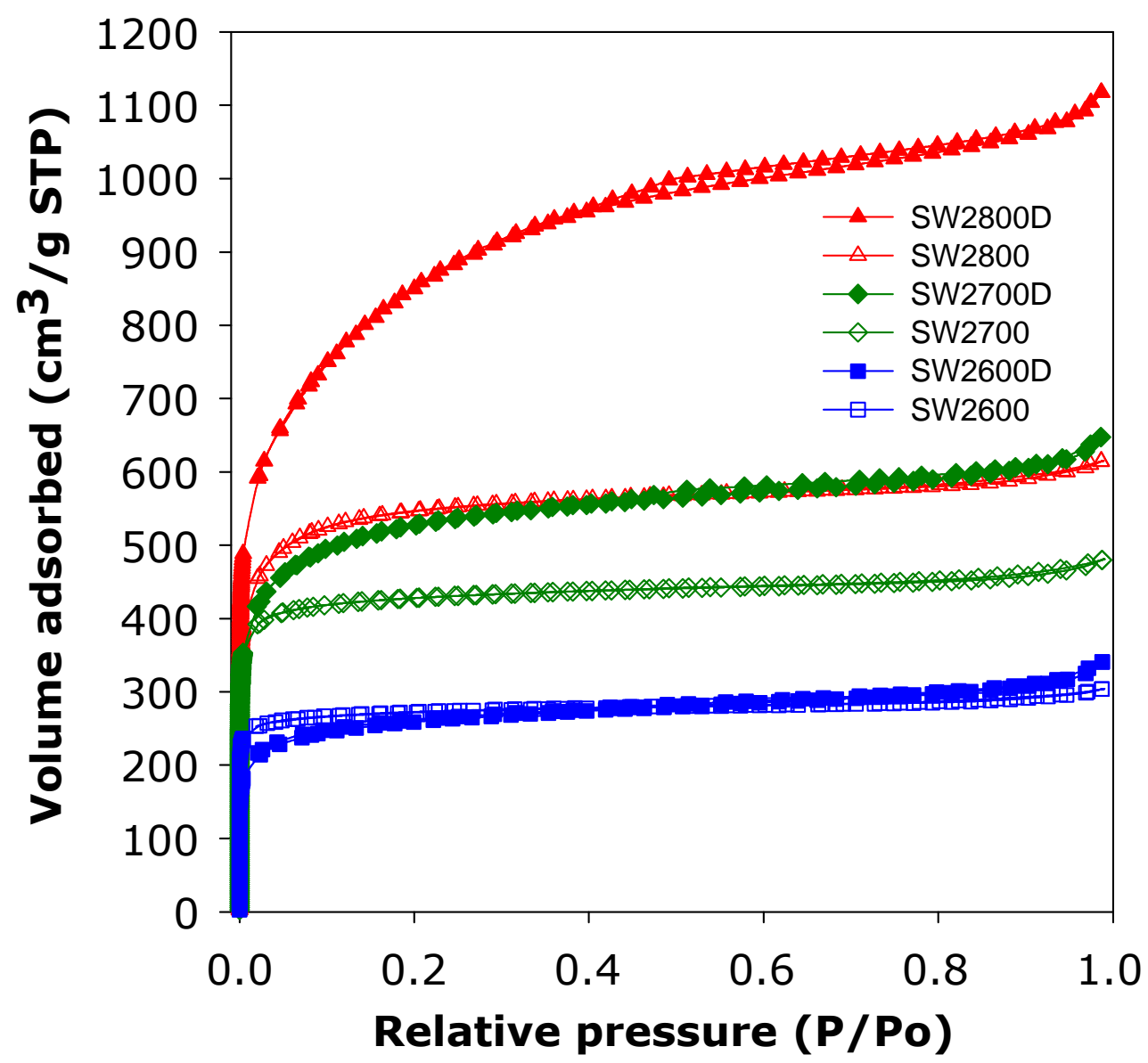

Supporting Figure S8. Nitrogen sorption isotherms of directly activated (SW2TD) or conventionally generated, via hydrothermal carbonisation, (SW2T) carbons derived from seaweed (Sargassum fusiforme). The carbons were prepared at $\mathrm{KOH} /$ carbon ratio of 2. 

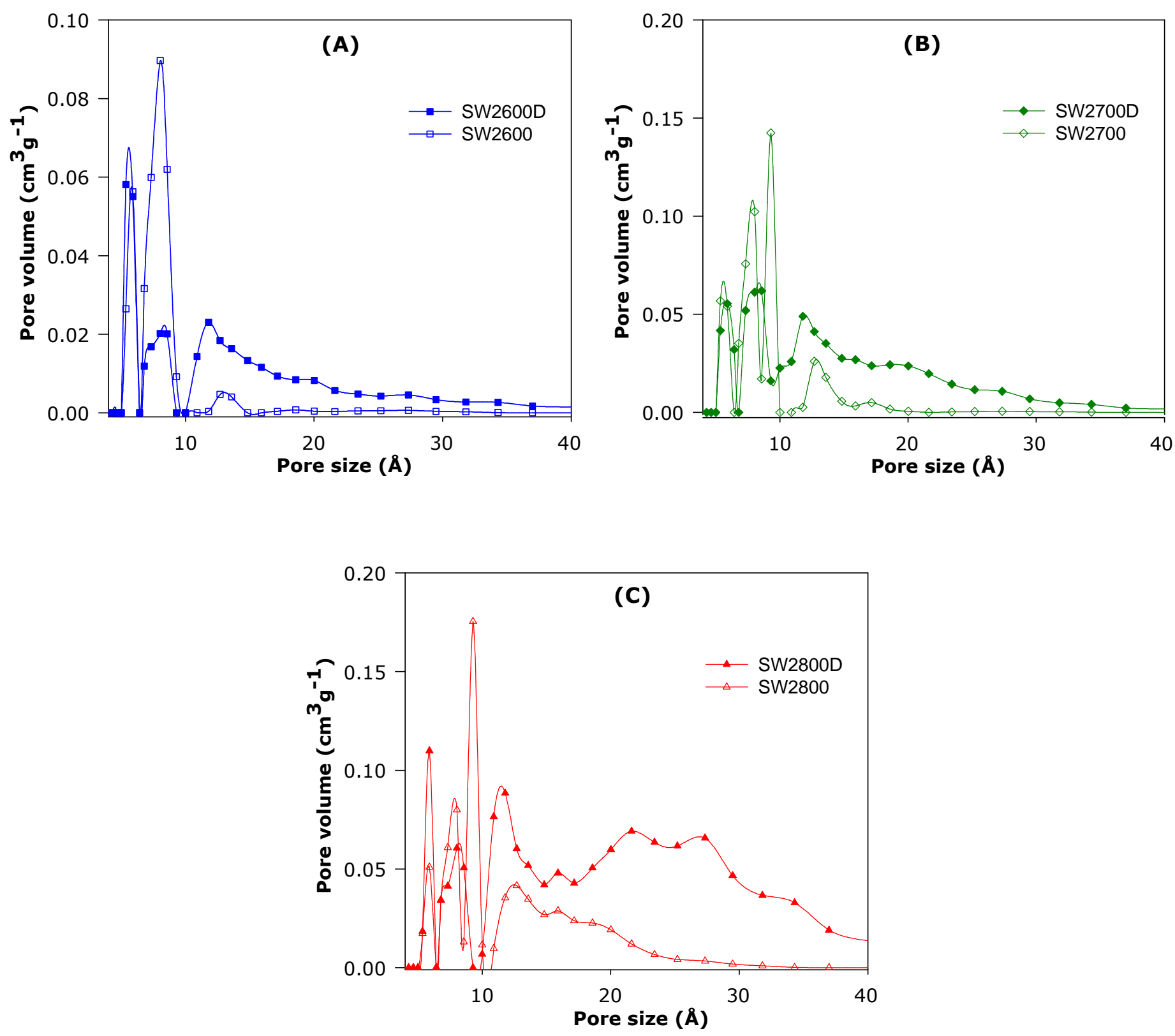

Supporting Figure S9. Pore size distribution curves of directly activated (SW2TD) or conventionally generated, via hydrothermal carbonisation, (SW2T) carbons derived from seaweed (Sargassum fusiforme). The carbons were prepared at $\mathrm{KOH} /$ carbon ratio of 2 and various temperatures; (A) $600{ }^{\circ} \mathrm{C}$, (B) $700{ }^{\circ} \mathrm{C}$ and (C) $800{ }^{\circ} \mathrm{C}$. 


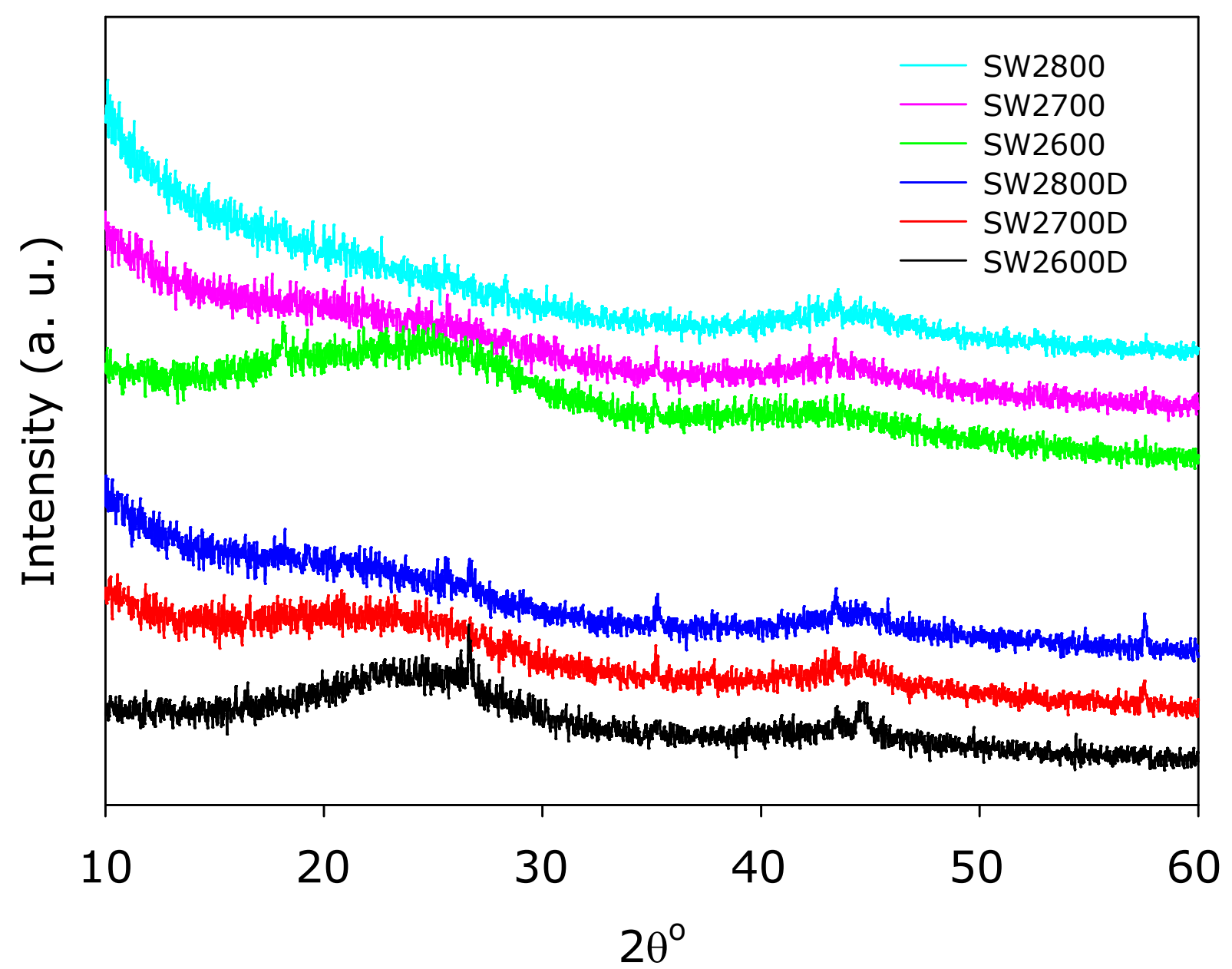

Supporting Figure S10. Powder XRD patterns of directly activated (SW2TD) or conventionally generated, via hydrothermal carbonisation, (SW2T) carbons derived from seaweed (Sargassum fusiforme). The carbons were prepared at $\mathrm{KOH} /$ carbon ratio of 2 . 

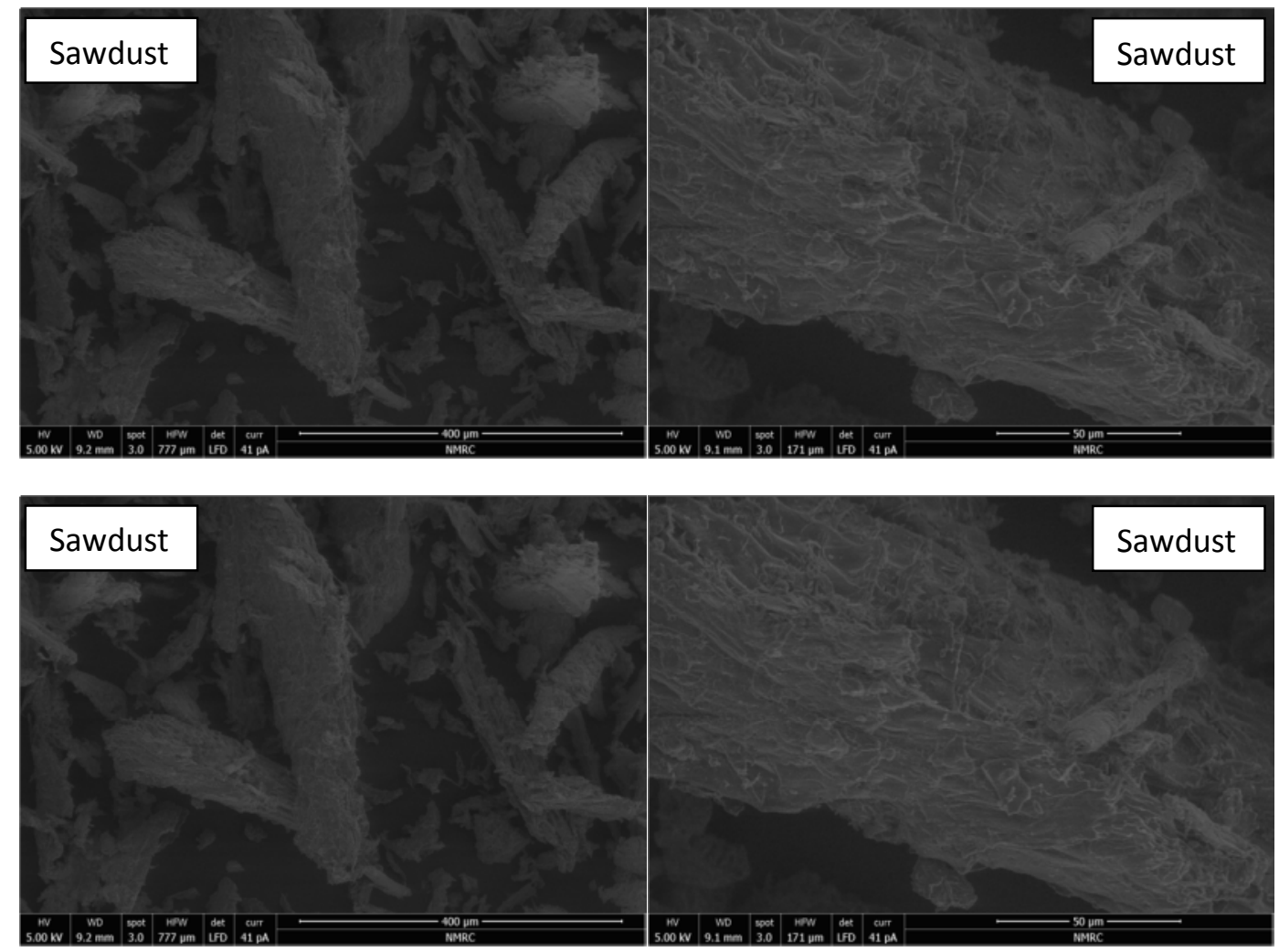

Supporting Figure S11. SEM images of raw sawdust. 

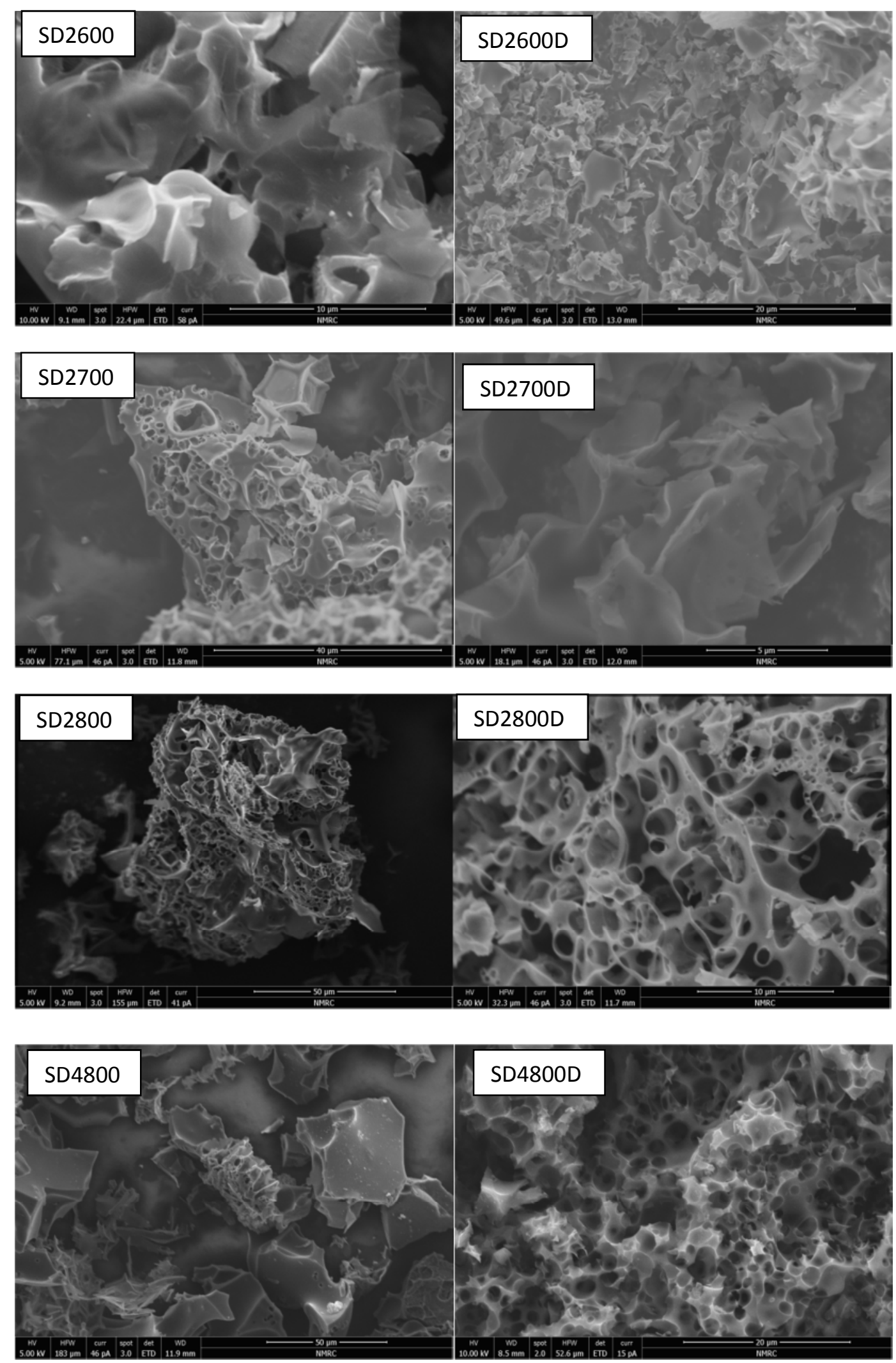

Supporting Figure S12. SEM images of sawdust-derived directly activated (SDxTD) or conventionally generated, via hydrothermal carbonisation, (SDxT) carbons. 

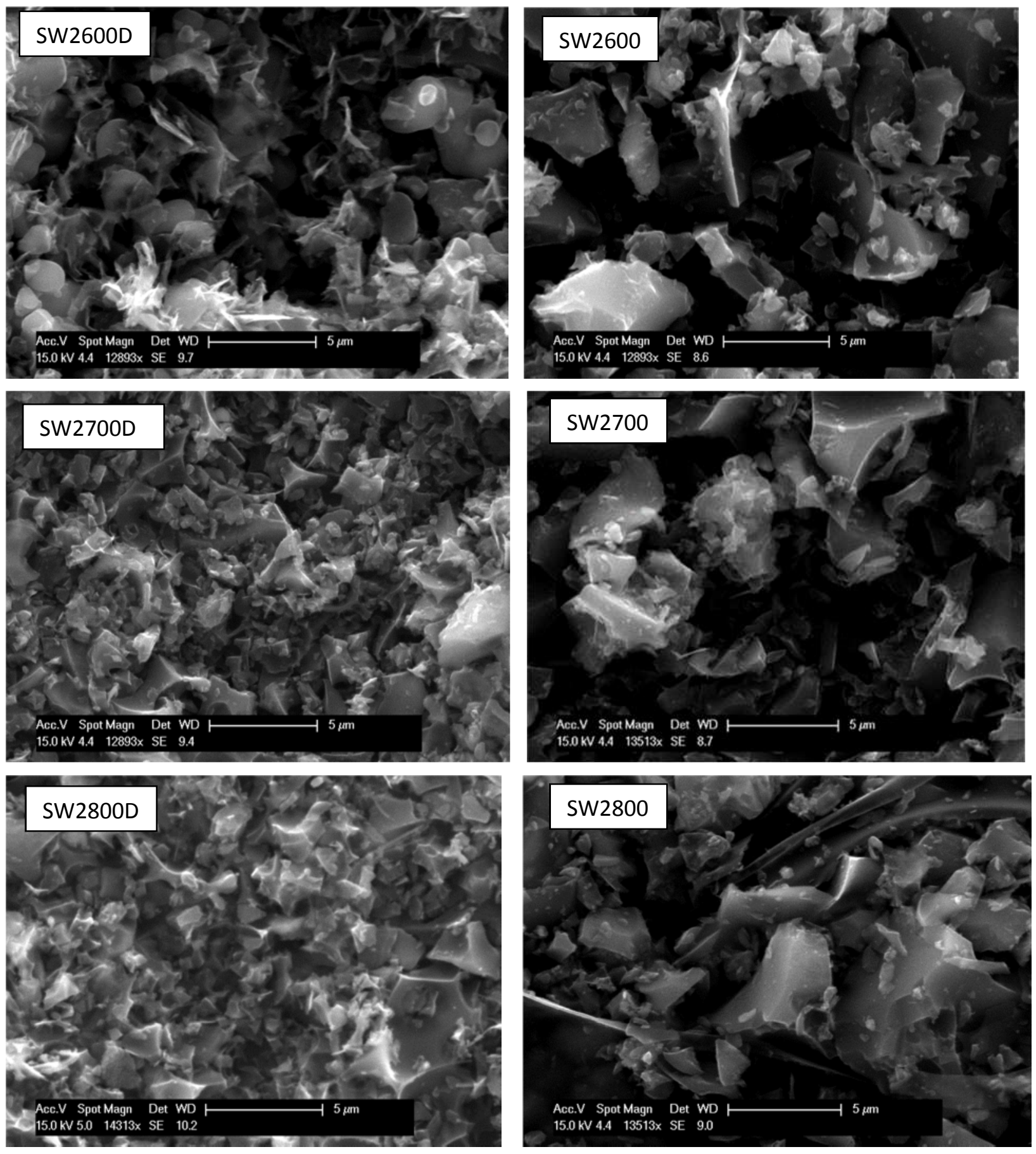

Supporting Figure S13. SEM images of directly activated (SW2TD) or conventionally generated, via hydrothermal carbonisation, (SW2T) carbons derived from seaweed (Sargassum fusiforme). The carbons were prepared at $\mathrm{KOH} /$ carbon ratio of 2. 

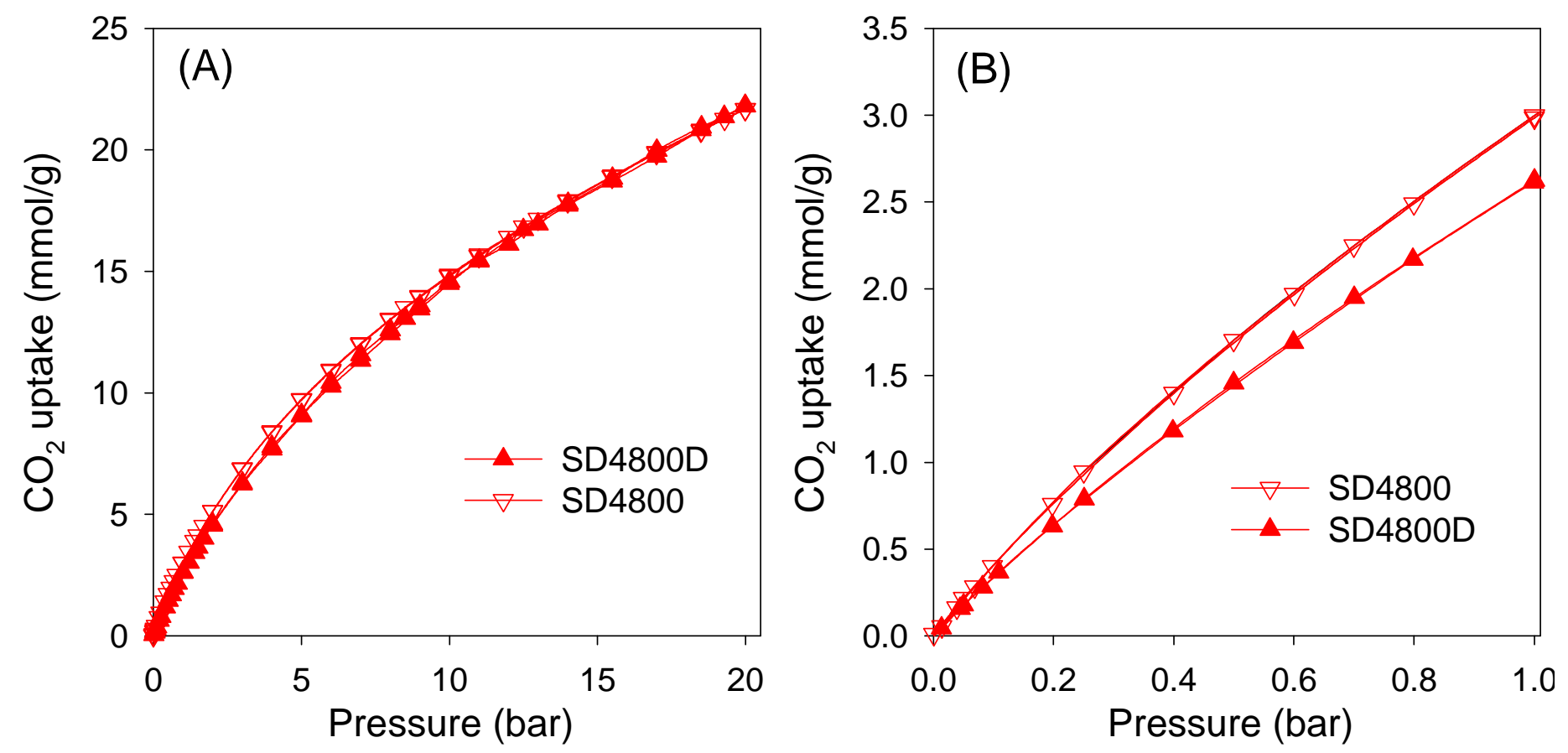

Supporting Figure S14. $\mathrm{CO}_{2}$ uptake isotherms at $25{ }^{\circ} \mathrm{C}$ and $0-20$ bar (A) and $0-1$ bar (B) for sawdust-derived directly activated (SD4800D) or conventionally generated, via hydrothermal carbonisation, (SD4800) carbons prepared at $800{ }^{\circ} \mathrm{C}$ and $\mathrm{KOH} /$ carbon ratio of 4. 

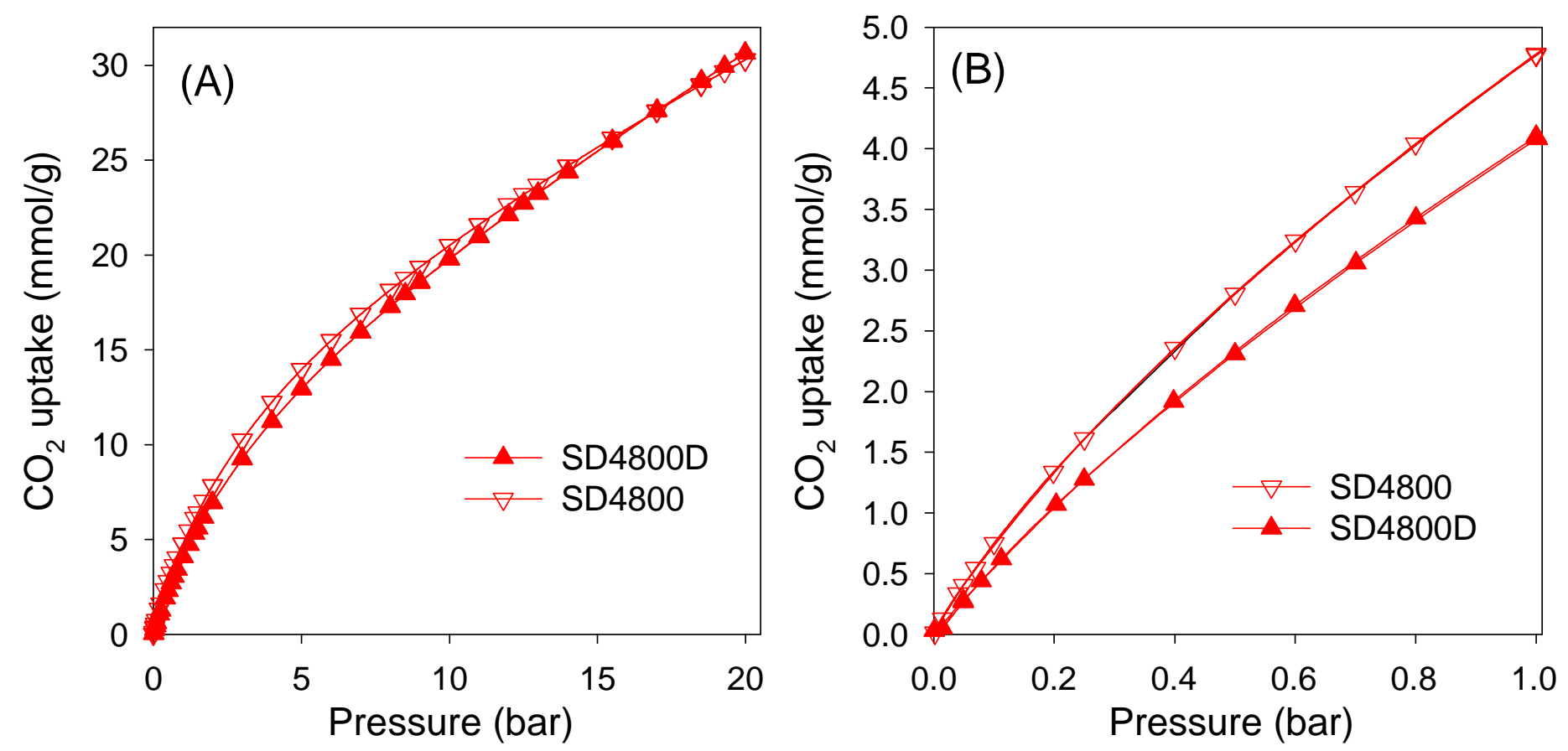

Supporting Figure S15. $\mathrm{CO}_{2}$ uptake isotherms at $0{ }^{\circ} \mathrm{C}$ and $0-20$ bar (A) and $0-1$ bar (B) for sawdust-derived directly activated (SD4800D) or conventionally generated, via hydrothermal carbonisation, (SD4800) carbons prepared at $800{ }^{\circ} \mathrm{C}$ and $\mathrm{KOH} /$ carbon ratio of 4. 

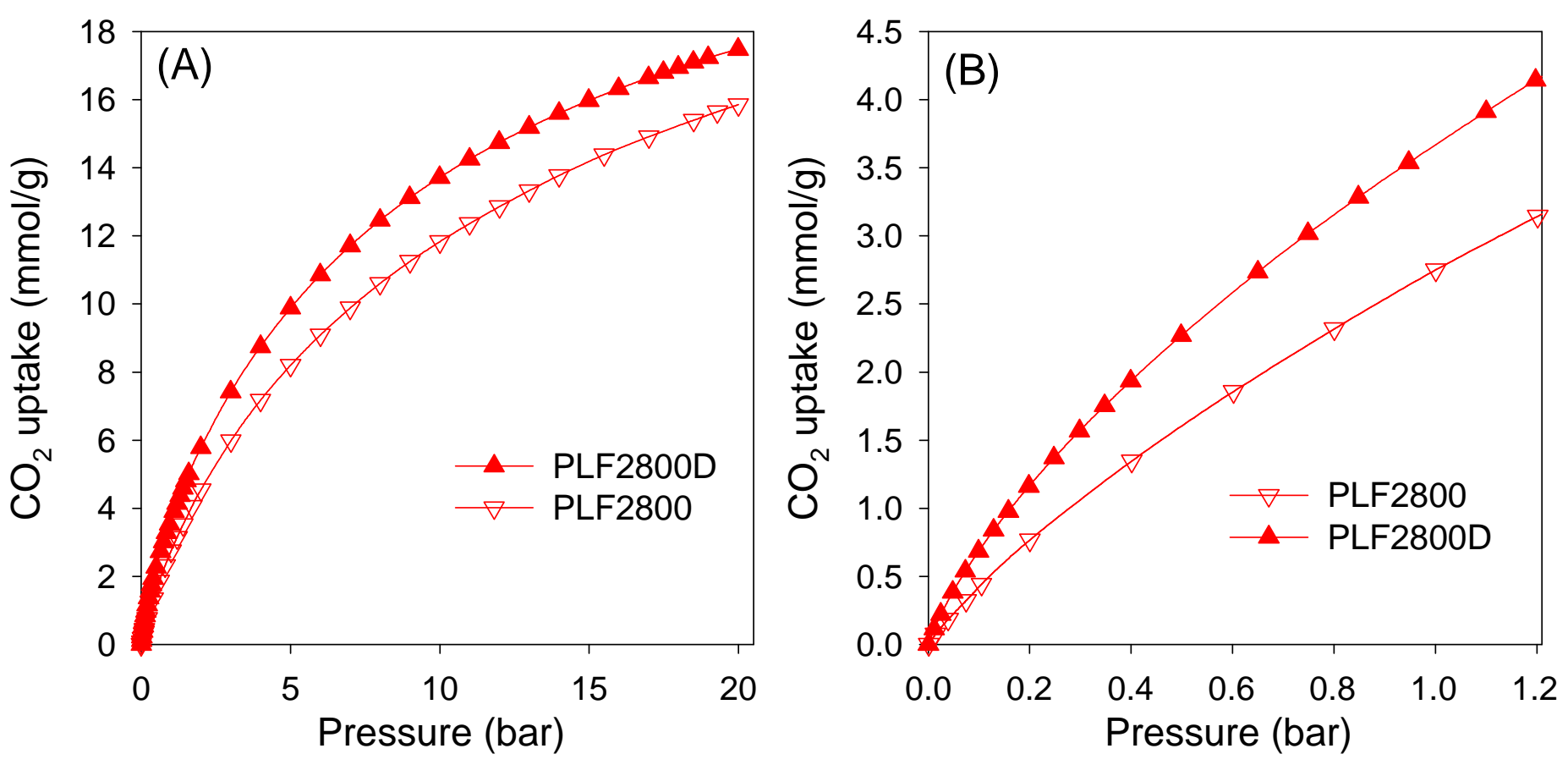

Supporting Figure S16. $\mathrm{CO}_{2}$ uptake isotherms at $25{ }^{\circ} \mathrm{C}$ and $0-20$ bar (A) and $0-1$ bar (B) for directly activated (PLF2800D) or conventionally generated, via hydrothermal carbonisation, (PLF2800) carbons derived from the flowering plant Paeonia Lactiflora. The carbons were prepared at $800{ }^{\circ} \mathrm{C}$ and $\mathrm{KOH} /$ carbon ratio of 2 . 


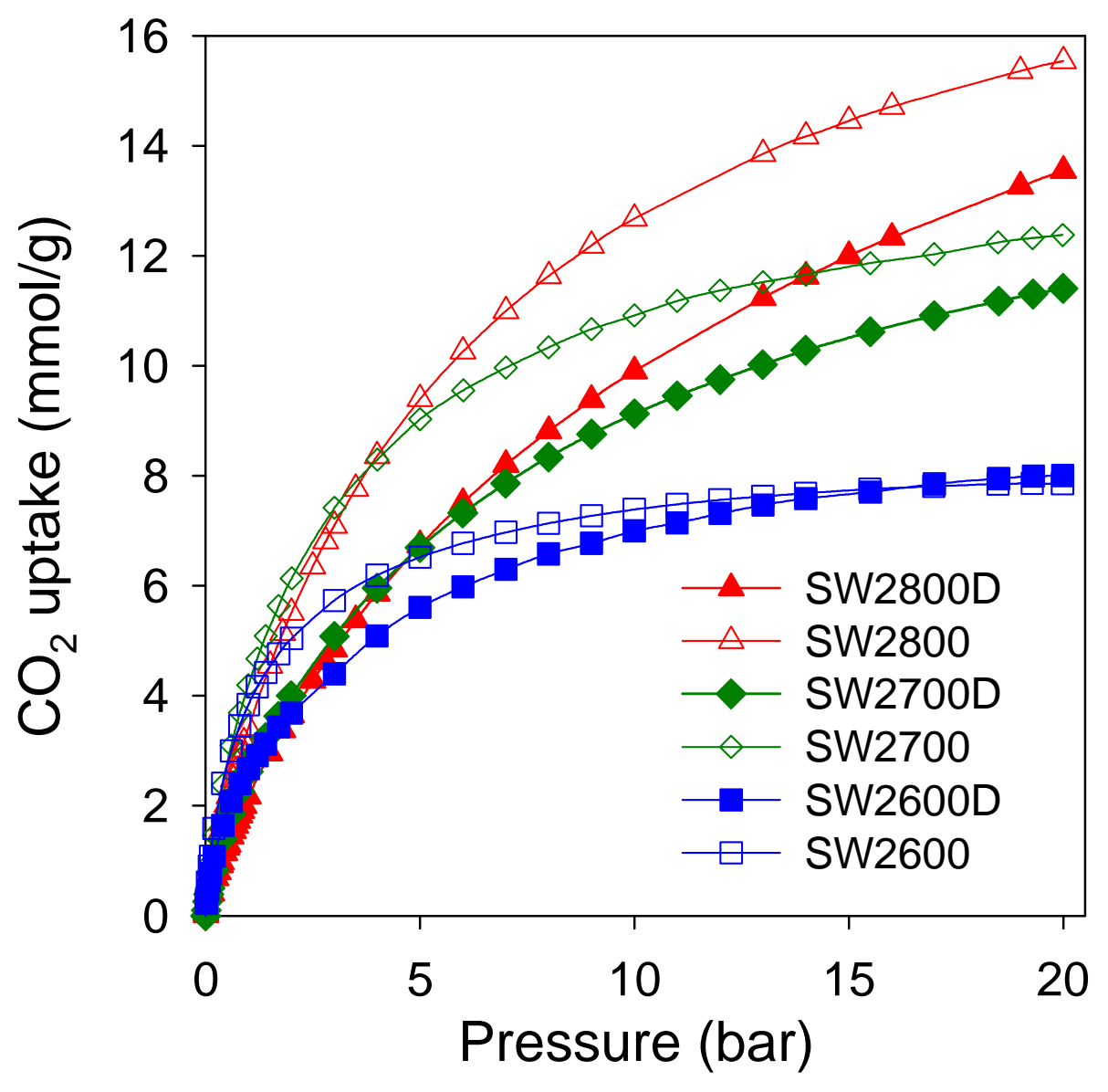

Supporting Figure S17. $\mathrm{CO}_{2}$ uptake isotherms at $25{ }^{\circ} \mathrm{C}$ and $0-20$ bar (A) and $0-1$ bar (B) for directly activated (SW2TD) or conventionally generated, via hydrothermal carbonisation, (SW2T) carbons derived from seaweed (Sargassum fusiforme). The carbons were prepared at $\mathrm{KOH} /$ carbon ratio of 2 . 